\title{
El consumo cultural en España. Una aproximación al análisis de la estratificación social de los consumos culturales y sus dificultades metodológicas.
}

\author{
Cultural consumption in Spain. An approach to the social \\ stratification of cultural consumptions and its methodological difficulties
}

\author{
Manuel Herrera-Usagre. \\ Fundación Centro de Estudios Andaluces (ESPAÑA) \\ manuelhusagre@gmail.com
}

Recibido: 27.07 .2010
Aceptado: 14.04 .2011

\section{RESUMEN}

La Sociología ha acudido con frecuencia al estudio de las clases sociales y del estatus social para explicar las diferencias en los hábitos y las prácticas culturales. Con el presente artículo hemos pretendido acotar las características sociales que tienen mayor influencia sobre los hábitos de consumo cultural. Para ello, hemos utilizado el marco que nos proporciona el conjunto de teorías más importantes sobre la estratificación social en el consumo cultural, a saber: el argumento de la homología; el argumento de la individualización; y el argumento de la omnivoridad. Paralelamente, expondremos las dificultades metodológicas que plantean diferentes técnicas estadísticas con las que la tradición sociológica reciente ha estudiado la estratificación social del consumo cultural. Tras nuestros análisis hemos comprobado cómo los consumos culturales siguen presentando características de estratificación social en la sociedad española contemporánea. Hemos encontrado evidencias de cómo prácticas consideradas de «alta cultura» están asociadas a los estratos mejor posicionados. No obstante, hemos encontrado evidencias importantes, aunque no decisivas, de cómo el argumento de la homología pierde poder explicativo en favor del argumento de la omnivoridad. Estos hallazgos complementan lo que ya otros trabajos sobre la omnivoridad han descubierto. Además, hemos encontrado patrones de consumo unívoro diferentes y particulares en nuestro país en lugar de un único patrón de consumo cultural unívoro. 


\title{
PALABRAS CLAVES
}

Estratificación social, consumo cultural, homología, individualización, omnivoridad.

\begin{abstract}
Oftentimes sociology has focussed on the relationship between social origin and cultural habits. In this paper we study the social characteristics that have most influence on patterns of cultural consumption. Sociology has often addressed the study of social class and social status by explaining differences in habits and cultural practices (social uses). In this paper, we try to identify what social characteristics are most influential in the segmentation of cultural habits. To do this, we test a set of theories that examines the role of social stratification in the consumption of cultural goods and services, and, thereby, check its explanatory power in Spain. We use the framework that gives us the most important set of theories on social stratification in cultural consumption, namely the homology argument, the individualisation argument and the Omnivore-Univore argument. Simultaneously, we deal with the methodological difficulties posed by the different statistical techniques used in recent sociological tradition over social stratification of cultural consumption. Our results prove that cultural consumption reflects social stratification in contemporary Spanish society. We found evidence of how practices which are considered as «high culture» are associated with better positioned strata. Nevertheless, we find important evidence, although not decisive, that the homology argument loses explanatory power in favour of the omnivore-univore argument. These findings complement what other omnivourness research works have discovered in recent years. Finally, we have found several univore comsumptions patterns for Spain instead of just one univore cultural consumption pattern.
\end{abstract}

\section{KEYWORDS}

Social stratification, cultural consumption, homology, individualization, omnivourness.

\section{INTRODUCCIÓN}

Las relaciones que guarda el origen social con los hábitos culturales han sido objeto de estudio privilegiado en las ciencias sociales. La sociología ha acudido con frecuencia al estudio de las clases sociales y del estatus social para explicar las diferencias en los hábitos y las prácticas culturales (sus usos sociales). En este 
sentido, «la estratificación del consumo cultural ha sido exhaustivamente estudiada en las sociedades industrializadas, particularmente en las áreas de la música, la asistencia a museos y las representaciones artísticas» (Torche, 2007: 71). No obstante, su análisis no ha estado exento de dificultades tanto en el plano de la praxis como el plano teórico. Con el presente artículo hemos pretendido acotar las características sociales que tienen mayor influencia sobre los hábitos de consumo cultural. Para ello, hemos utilizado el marco que nos proporciona el conjunto de teorías más importantes sobre la estratificación social en el consumo cultural y comprobar así su capacidad explicativa en nuestro país. Paralelamente, hemos comprobado las dificultades metodológicas que plantean las diferentes técnicas estadísticas con las que se pretenden comprobar dichas teorías.

El documento se divide en tres grandes bloques. En el primero, describiremos brevemente las diferentes teorías sobre consumo cultural y estratificación social más importantes en la actualidad. En un segundo bloque, presentaremos los resultados de nuestro estudio en los que encontraríamos varios análisis multivariables. Finalmente, presentaremos las conclusiones y discusiones teóricas, metodológicas y de resultados que han emergido de nuestra investigación. Las bases de datos que utilizaremos serán tres. Una es la Encuesta de Empleo del Tiempo realizada entre 2002 y 2003 por el Instituto Nacional de Estadística. Con ella efectuaremos análisis de regresión logística sobre la probabilidad de acudir a un conjunto de eventos culturales. También utilizaremos la Encuesta de Estructura y Clases Sociales de 2006, realizada por el Centro de Investigaciones Sociológicas. Con ella realizaremos un análisis de correspondencias múltiples con un conjunto de variables sobre consumo cultural y estilos de vida. Por último vamos a utilizar la Encuesta de Hábitos y Prácticas Culturales de 2006-2007 realizada por el Ministerio de Cultura en colaboración con la Sociedad General de Autores y Editores. Con ella realizaremos un análisis de clases latentes con los géneros musicales que más habitualmente escucha la población.

\section{ESTRATIFICACIÓN SOCIAL Y CONSUMO CULTURAL}

Son tres los argumentos que según Chan y Goldthorpe (2007a, 2007b, 2007 c) constituyen el grueso de enfoques al respecto. En primer lugar, se encuentra el argumento de la homología, que achaca las razones implícitas para los diferentes estilos de vida y consumos culturales al factor estructural de las clases sociales y/o el estatus. En segundo lugar, el argumento de la individualización defiende que, gracias a la universalización del acceso a la cultura en las sociedades contemporáneas, las diferencias en los estilos de vida y consumos culturales están únicamente sustentadas por la voluntad del individuo. En último lugar, el argumento de la omnivoridad defiende que los gustos no son casillas-estancos de propiedad exclusiva de las diferentes clases sociales, sino que la diferencia fundamental reside en cuanto del abanico de consumos culturales es capaz cada estrato de abarcar.

EMPIRIA. Revista de Metodología de Ciencias Sociales. N. ${ }^{\circ}$ 22, julio-diciembre, 2011, pp. 141-172. ISSN: $1139-5737$ 


\subsection{Argumento de la homología}

Según Chan y Goldthorpe (2006: 1; 2007b: 168), este enfoque sostiene que existe un estrecho solapamiento entre la estratificación social y los gustos y hábitos culturales. Los individuos de los estratos sociales más altos tienen gustos y consumos típicos de la «alta cultura»o «cultura de élite». En cambio, los individuos de los estratos más bajos tienen consumos y gustos más relacionados con lo que se denomina «baja cultura», «cultura popular» o «cultura de masas».

Esta división antagónica ya la cita en La Deshumanización del Arte de 1925 José Ortega y Gasset, cuando realiza un breve pero interesantísimo análisis de los efectos sociales del arte nuevo -entendiendo este como arte de vanguardia-:

Lo característico del arte nuevo, desde el punto de vista sociológico, es que divide al público en estas dos clases de hombres: los que lo entienden y los que no lo entienden. [...] Por otra parte, el arte joven [nuevo] contribuye también a que los «mejores» se conozcan y reconozcan entre el gris de la muchedumbre y aprendan su misión, que consiste en ser pocos y tener que combatir contra los muchos (Ortega y Gasset, 2008: 48).

Es precisamente esta escisión la que Pierre Bourdieu examina, desde una perspectiva menos elitista y más empírica, en su trabajo más importante, La Distinction (2006). Para Bourdieu, es innegable una correspondencia entre los hábitos y la clase social de los individuos. Esta homología está marcada por lo que él denomina habitus de clase. Esto es, un «sistema de disposiciones» que los miembros de una clase adquieren bajo las condiciones materiales y simbólicas de existencia en las que han crecido. Dicho de otro modo, el habitus de clase es una unidad semántica que aglutina una diversidad de prácticas en todos los dominios del consumo, incluido el cultural. Este modo de diferenciación crea una estructura jerárquica de los gustos y los estilos de vida, expresada a su vez en un orden de estatus. El enfrentamiento entre «órdenes de hombres» que presentaba Ortega y Gasset, se traduce en el pensamiento bourdiano como una lucha entre clases en el campo de lo simbólico, donde se ejercen dinámicas de inclusión y exclusión, igualdad y diferencia entre los individuos. Esta violencia simbólica de distinción y superioridad de sus propios estilos de vida, lleva a una reproducción cultural de los habitus. Y es esta reproducción cultural la clave según autores como Jenkins (2002: 147), para entender la reproducción social.

\subsection{Argumento de la individualización}

Según el enfoque de la individualización, las bases del gusto y los hábitos culturales no están tan relacionadas con la estratificación social, sino con un ejercicio individual de auto-realización. En las sociedades económicamente avanzadas y democráticamente desarrolladas se ha producido un debilitamiento de la 
influencia de la clase o el estatus como factor de influencia en los estilos de vida (Pakulski y Waters, 1996). Los individuos al tener acceso a un mayor rango de opciones, se alinean ellos mismos con aquellas colectividades en las que consideran que van a poder formar y recrear sus identidades más cómodamente (Giddens, 1991; Beck, 1992).

En versiones más recientes y de una mayor radicalidad posmoderna, los estilos de vida son desposeídos de cualquier influencia de carácter estructural. Los individuos son cada vez más libres y capaces de formar sus estilos de vida, independientemente de los background sociales que conserven. Es pues, que el consumo y el gusto es una forma de construir su propia identidad (Bauman, 1988; 2002). Debido a la inmensa variedad de posibilidades altamente comercializadas que la sociedad de consumo ofrece a los individuos, se ha pasado del «poder elegir» al «tener que elegir» los bienes y servicios que marcarán nuestros estilos de vida. He aquí la diferencia fundamental del enfoque de la individualización con respecto a las teorías del «aburguesamiento de la clase obrera ${ }^{1} »$. No es una cuestión de adopción vertical ascendente de estilos de vida de una clase a otra. Sino que la construcción del gusto no está limitada a cuestiones estratificatorias y por tanto, los hábitos culturales antes restringidos a una u otra clase, se liberan de esos cabos y se reparten de igual modo en todos los estratos. «Del habitus a la libertad» es una sentencia de Warde (1997) que remarca la distancia que este enfoque tiene de las tesis de Bourdieu.

\subsection{Argumento de la omnivoridad}

Según apuntan Chan y Goldthorpe (2007b: 170) lo primero que hay que destacar de este enfoque es que analiza más los consumos culturales que los estilos de vida en general. El estudio que establece los cimientos de este enfoque fue el desarrollado por Wilensky (1964). En él, argumentaba que las personas con altos niveles educativos no sentían aversión alguna por lo que conocemos como cultura de masas -como defiende el argumento de la homología-, sino que por el contrario la consumían en alguna de sus formas. Más recientemente, DiMaggio y Useem (1978), DiMaggio (1987), Peterson y Simkus (1992) y Peterson y Kern (1996) defienden que en las sociedades contemporáneas el argumento de la homología ha perdido validez, no porque el consumo cultural ya no esté influenciado por la estratificación social, sino porque una nueva relación entre ambos ha surgido. El consumo cultural de los individuos de estatus alto no se corresponde con hábitos y prácticas de productos exclusivos y excluyentes. El contraste entre los diferentes estratos reside en la amplitud del rango de géneros culturales que consume. A diferencia de los individuos de estratos más bajos, los de estratos al-

\footnotetext{
${ }^{1} \mathrm{Su}$ enfoque destaca entre otros cambios, un progresivo acercamiento de los modos y estilos de vida de la nueva clase obrera -obreros y operarios manuales con formación especializada- hacia los de las clases intermedias - trabajadores no manuales de bajo rango. A pesar de este acercamiento, esto, como señala Goldthorpe (1968: 27), no es sinónimo de identidad.
} 
tos no solo consumen más de alta cultura, sino consumen más media cultura y baja cultura, y no de un modo indiscriminado sino siendo extremadamente selectivo con las obras de cada rango de consumo cultural. De este modo, los estratos altos desarrollarían un cierto «eclecticismo del gusto» (Peterson, 2005), que les permite disfrutar de una amplia gama de productos y servicios culturales asî como de los diferentes géneros existentes. En cambio, el resto de estratos sociales tendrían más restringida su capacidad de disfrute de la oferta de géneros, productos y servicios culturales, limitándose solo a algunos de ellos.

Este paradigma ha permitido una ingente producción científica en la materia. No obstante también ha fomentado la discusión y el debate abierto en diferentes foros, incluyendo monográficos y proyectos de investigación. Aquellas posiciones críticas, podemos clasificarlas entre, por un lado, las que cuestionan los presupuestos teóricos del paradigma (Ryan, 2000; Warde, Wright y Gayo-Cal, 2007; Lahire, 2008) y por otro lado, aquellas que lo hacen desde el plano metodológico-técnico (Bryson, 1996; Silva, 2006; Wuggenig, 2007; Peterson, 2005; 2007; Ollivier, 2008).

\section{ANÁLISIS DE LAS PRÁCTICAS CULTURALES EN ESPAÑA}

Después de ver las características principales de los enfoques teóricos más importantes, vamos a abordar los análisis multivariables que probarán la vigencia de las diferentes teorías sobre la estratificación social del consumo cultural en nuestro país.

Para ello utilizaremos los tres análisis multivariables que comentamos al inicio del artículo.

\subsection{La probabilidad de asistir a eventos culturales}

A continuación vamos a comprobar que características sociodemográficas son las más influyentes a la hora de predecir el hecho de ir o no ir a diferentes eventos culturales. Para ello utilizaremos las variables sociodemográficas más comunes en los estudios de estratificación social: sexo, edad, estado civil, nivel educativo, clase social, medida según el esquema EGP o CASMIN de Erikson, Goldthorpe y Portocarero (1979) ${ }^{2}$, ingresos y el estatus socioeconómico, medido a través del International Socio-Economic Index (ISEI) de Ganzeboom, De Graaf y Treiman $(1992)^{3}$. El estatus socioeconómico y las clases sociales forman parte de un mismo fenómeno de estratificación social. Ambas herramientas se

\footnotetext{
${ }^{2}$ Ver Anexo A1 para una descripción detallada de las profesiones que componen cada una de las clases. El esquema utilizado para este análisis es la versión adaptada (7 clases).

${ }^{3}$ Este índice de estatus pretendía ser una adaptación a escala internacional del Socio-Economic Index (SEI) que Duncan diseñó para los Estados Unidos. Según Carabaña y Gómez Bueno (1996:
} 
utilizan con el fin de ver cuál de ellas tiene un mayor poder explicativo sobre diferentes fenómenos sociales.

El estudio de clase permite ordenar las distintas unidades que componen el esquema de acuerdo con el tipo y la cantidad de recursos (tanto sociales como materiales) de los que disponen los individuos. En efecto, el estudio de los consumos culturales nos provee de una buena herramienta para comprobar esa distribución desigual de recursos.

A diferencia del anterior instrumento de estratificación social, las escalas de prestigio ocupacional o estatus pretenden proveer al investigador social de una herramienta útil para la clasificación ordinal de las profesiones con el objetivo de compararlas globalmente. Sintetizan toda la información que contienen las diferentes profesiones u oficios (ingresos, nivel educativo, autonomía, complejidad, tasas de paro, etc.) de manera que podamos compararlas entre sí. Carabaña y Gómez Bueno afirman que «el prestigio tiene una naturaleza socioeconómica y que el índice socioeconómico de Duncan (SEI) [como escala de estatus] es una buena aproximación al prestigio» (1996: 18). No obstante, De Graaf, Ganzeboom y Treiman eran «partidarios de considerar a los índices de estatus simplemente como tales, no como medidas indirectas del prestigio» (1996: 44) y crearon, en consecuencia, una escala de medida de estatus social de diera cuenta de las desigualdades socioeconómicas prescindiendo de la información sobre el prestigio.

La adecuación de una u otra herramienta para el estudio del consumo de bienes y servicios culturales ha de ser establecida tras la utilización de técnicas multivariables. A continuación, vamos a mostrar que tipo de fenómenos culturales queremos predecir a través de las anteriores herramientas de estratificación social, ceteris paribus.

Los sucesos que queremos predecir son: ir al cine; ir al teatro, danza o ballet; ir a conciertos de música; realizar visitas monumentos histórico-artísticos; y visitar museos y/o exposiciones de arte. Para llevar a cabo este análisis emplearemos la técnica multivariable de regresión logística. Esta técnica de causalidad probabilística es utilizada para predecir un suceso - v.g. ir al cine o no - a partir de un conjunto de variables explicativas - v .g sexo -. Este tipo de regresión esta especialmente diseñada para las variables dependientes de tipo categórico, como es nuestro caso. La encuesta utilizada será la Encuesta de Empleo del Tiempo (INE, 2003; $n=19.807$ casos una vez eliminados los valores perdidos). En la tabla 1 se muestran todos los resultados de estos análisis.

44) «en el ISEI el valor de una ocupación radica en la fidelidad con que transforma la educación en ingresos». A través de la utilización de una impresionante base de datos longitudinales en 16 países, los autores ordenaron las profesiones de manera que reflejaran «la correspondencia que una inversión en educación encuentra -en un determinado campo- en los ingresos a percibir en el mercado laboral» (1996: 44). Incluir las variables nivel educativo e ingresos en el modelo, además del ISEI, responde a varios motivos. En primer lugar, es una manera de controlar un posible efecto de desajuste entre educación e ingresos a la hora de predecir ciertos comportamientos, como los consumos culturales. En segundo lugar, replicamos el modus operandi de anteriores estudios en la materia como son los realizados por Chan y Goldthorpe (2007a, 2007b, 2007c). 
Tabla 1. Determinantes sociales para la realización de actividades culturales en sus diferentes áreas

\begin{tabular}{|c|c|c|c|c|c|c|c|c|c|c|}
\hline & \multicolumn{2}{|c|}{ Cine } & \multicolumn{2}{|c|}{$\begin{array}{c}\text { Teatro, Danza o } \\
\text { Ballet }\end{array}$} & \multicolumn{2}{|c|}{$\begin{array}{l}\text { Conciertos de } \\
\text { Música }\end{array}$} & \multicolumn{2}{|c|}{$\begin{array}{c}\text { Monumentos } \\
\text { histórico-artísticos }\end{array}$} & \multicolumn{2}{|c|}{$\begin{array}{c}\text { Museos y } \\
\text { Exposiciones de } \\
\text { Arte }\end{array}$} \\
\hline & $\beta$ & $\begin{array}{c}\text { Error } \\
\text { Std. }\end{array}$ & $\beta$ & $\begin{array}{l}\text { Error } \\
\text { Std. }\end{array}$ & $\beta$ & $\begin{array}{c}\text { Error } \\
\text { Std. }\end{array}$ & $\beta$ & $\begin{array}{c}\text { Error } \\
\text { Std. }\end{array}$ & $\beta$ & $\begin{array}{c}\text { Error } \\
\text { Std. }\end{array}$ \\
\hline Hombre $^{a}$ & $-0,161 * *$ & $(0,038)$ & $0,436^{* *}$ & $(0,069)$ & $-0,022$ & $(0,056)$ & $-0,120^{*}$ & $(0,052)$ & $0,192^{* *}$ & $(0,057)$ \\
\hline Casado $^{\text {b }}$ & $-0,866^{* *}$ & $(0,044)$ & $0,489^{* *}$ & $(0,082)$ & $0,840^{* *}$ & $(0,067)$ & $0,237^{* *}$ & $(0,063)$ & $0,406^{* *}$ & $(0,068)$ \\
\hline $\begin{array}{l}\text { Separado o } \\
\text { divorciado }\end{array}$ & $-0,168$ & $(0,086)$ & $-0,098$ & $(0,150)$ & $0,344^{* *}$ & $(0,133)$ & $-0,287^{*}$ & $(0,129)$ & $0,346^{* *}$ & $(0,134)$ \\
\hline Edad & $-0,075 * *$ & $(0,010)$ & $0,059^{* *}$ & $(0,020)$ & $0,058^{* *}$ & $(0,015)$ & $0,039^{*}$ & $(0,015)$ & $0,097 * *$ & $(0,017)$ \\
\hline Edad2 & $0,000 * *$ & $(<0,001)$ & $<0,001 *$ & $(<0,001)$ & $0,001 * *$ & $(<0,001)$ & $<0,001^{*}$ & $(<0,001)$ & $0,001^{* *}$ & $(0,000)$ \\
\hline Ingresos & $0,271 * *$ & $(0,034)$ & $0,279 * *$ & $(0,066)$ & 0,094 & $(0,052)$ & $0,189^{* *}$ & $(0,049)$ & $0,131 * *$ & $(0,053)$ \\
\hline $\begin{array}{l}\text { Educación } \\
\text { primaria }^{c}\end{array}$ & $0,586 * *$ & $(0,053)$ & $0,653 * *$ & $(0,111)$ & $0,552 * *$ & $(0,084)$ & $0,725^{* *}$ & $(0,080)$ & $0,953 * *$ & $(0,089)$ \\
\hline $\begin{array}{l}\text { Bachiller, } \\
\text { BUP o FP }\end{array}$ & $0,461 * *$ & $(0,044)$ & $0,780 * *$ & $(0,095)$ & $0,488 * *$ & $(0,072)$ & $0,769^{* *}$ & $(0,068)$ & $0,939 * *$ & $(0,078)$ \\
\hline Universitaria & $0,708^{* *}$ & $(0,071)$ & $0,916^{* *}$ & $(0,125)$ & $0,691 * *$ & $(0,103)$ & $1,295^{* *}$ & $(0,092)$ & $1,414 * *$ & $(0,102)$ \\
\hline Clase II ${ }^{\mathrm{d}}$ & $-0,087$ & $(0,088)$ & $-0,247$ & $(0,130)$ & $-0,146$ & $(0,117)$ & $-0,097$ & $(0,104)$ & $-0,125$ & $(0,106)$ \\
\hline Clase III & 0,105 & $(0,081)$ & $-0,227$ & $(0,130)$ & $-0,246^{*}$ & $(0,112)$ & 0,016 & $(0,100)$ & $-0,208$ & $(0,107)$ \\
\hline Clase IV & $-0,288^{* *}$ & $(0,105)$ & $-0,437 *$ & $(0,183)$ & $0,385^{* *}$ & $(0,157)$ & $0,394^{* *}$ & $(0,143)$ & $0,608^{* *}$ & $(0,155)$ \\
\hline Clase V & $-0,068$ & $(0,186)$ & $-0,222$ & $(0,339)$ & $-0,407$ & $(0,310)$ & 0,161 & $(0,238)$ & $-0,498$ & $(0,301)$ \\
\hline Clase VI & 0,001 & $(0,103)$ & $0,708^{* *}$ & $(0,187)$ & $-0,352^{*}$ & $(0,149)$ & $-0,242$ & $(0,138)$ & $0,538^{* *}$ & $(0,153)$ \\
\hline Clase VII & $-0,113$ & $(0,126)$ & $0,763^{* *}$ & $(0,243)$ & $-0,366$ & $(0,189)$ & $-0,302$ & $(0,178)$ & $0,519^{* *}$ & $(0,196)$ \\
\hline Estatus & $0,017 * *$ & $(0,002)$ & $0,008^{*}$ & $(0,004)$ & $0,012 * *$ & $(0,003)$ & $0,010^{* *}$ & $(0,003)$ & $0,009^{* * *}$ & $(0,003)$ \\
\hline Constante & $-0,608$ & $(0,293)$ & $-6,224$ & $(0,578)$ & $-1,840$ & $(0,425)$ & $-4,971$ & $(0,430)$ & $-6,108$ & $(0,481)$ \\
\hline Pseudo R2 & 0,1 & & & 80 & 0,0 & 68 & & 975 & 0,1 & \\
\hline $\begin{array}{l}\text { Bondad del } \\
\text { Ajuste }\end{array}$ & -1094 & 9,350 & -405 &, 242 & -5670 &, 709 & -644 & 1,036 & -5514 & ,950 \\
\hline
\end{tabular}

$* p<0,05 ; * * p<0,01$.

Fuente: Encuesta de Empleo del Tiempo 2002-2003 (INE) y elaboración propia. $\mathrm{n}=19807$

${ }^{\text {a }}$ Mujer como categoría de referencia

${ }^{\mathrm{b}}$ Soltero como categoría de referencia

${ }^{\mathrm{c}}$ Menos de primaria como categoría de referencia

${ }^{\mathrm{d}}$ Clase I como categoría de referencia

La categoría de la primera variable, hombre, habría que relacionarla con su categoría de referencia, es este caso, mujer. En el caso de ir al cine vemos como el coeficiente beta toma el valor de $-0,161$. Esto quiere decir que un hombre tiene menos probabilidades de ir al cine, ya que su valor es negativo, que una mujer, siendo esta relación estadísticamente significativa. A tenor de esta tabla, ¿cuáles son las otras variables que, entonces, intervienen en la probabilidad 
de ir al cine? Pues bien, las probabilidades se incrementan a medida que el individuo tiene menor edad, mayores ingresos, mayor nivel educativo, mayor estatus socioeconómico y pertenece a la clase de servicio I en lugar de pertenecer en la clase de pequeños propietarios (IV).

Las mujeres también tienen más probabilidad de acudir al teatro, la danza o el ballet. Además, ésta probabilidad se incrementa a medida que el individuo tiene mayor edad, mayores ingresos, mayor nivel educativo, mayor estatus socioeconómico, y pertenece a la clase de servicio I en lugar de pertenecer a la clase de pequeños propietarios (IV), o a alguna de las clases de trabajadores manuales (VI y VII).

En el caso de ir a conciertos de música, las probabilidades aumentan si se es soltero pero esta vez no influye el sexo. También la probabilidad aumenta a medida que el individuo tiene menor edad, mayor nivel educativo, mayor estatus socioeconómico, y pertenece a la clase de servicio I en lugar de pertenecer a la clase no manual rutinaria (III), a la de pequeños propietarios (IV) o a la de trabajadores manuales cualificados (VI).

Figura 1. Probabilidad de ir al cine para un individuo medio (línea inferior) y para una mujer de 30 años con título universitario (línea superior) según el estatus socioeconómico

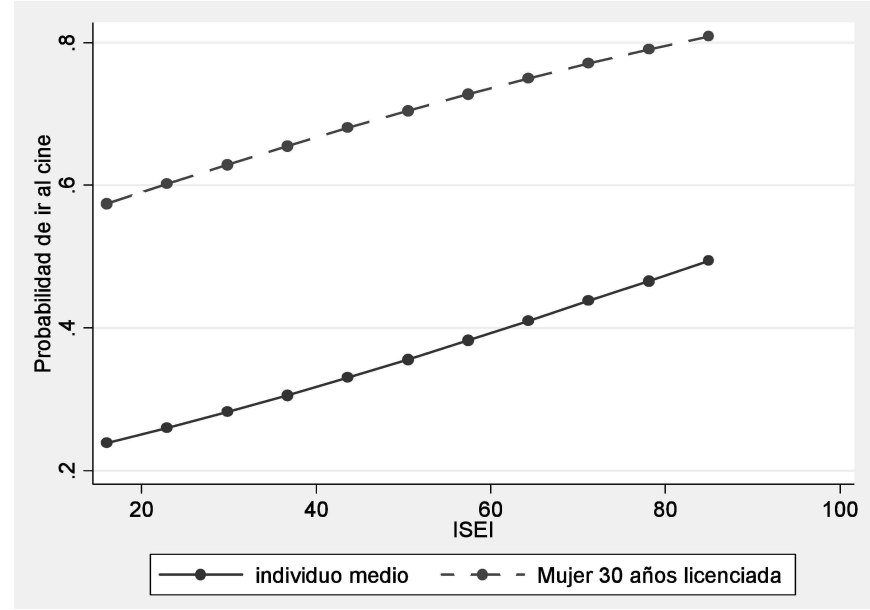

Fuente: Encuesta de Empleo del Tiempo 2002-2003 (INE) y elaboración propia.

Por otro lado, ser mujer y estar soltera aumenta las probabilidades de ir a monumentos histórico-artísticos. Junto a estas características, las probabilidades aumentarán a medida que el individuo tiene mayor edad, tiene mayores ingresos, mayor nivel educativo, mayor estatus socioeconómico y pertenece a la clase de servicio I, en lugar de pertenecer a la clase de pequeños propietarios (IV). Ocurre lo mismo en el caso de ir a museos y exposiciones de arte. Ser mujer, y tener 
un estado civil soltero aumentan las probabilidades de acudir a museos y exposiciones de arte. Además las probabilidades aumentarán a medida que el individuo tiene mayor edad, tiene mayores ingresos, mayor nivel educativo, y mayor estatus socioeconómico. En cambio, pertenecer a la clase de servicio I aumenta las probabilidades de ir a museos y exposiciones de arte, si las comparamos esta vez con la clase de pequeños propietarios (IV), y las clases de trabajadores manuales (VI y VII).

En la figura (1) simulamos la probabilidad de ir al cine a medida que aumenta el estatus social de los individuos (medido a través del índice ISEI). La línea inferior representa de qué forma aumenta la probabilidad de ir al cine a medida que aumenta el estatus socioeconómico para un individuo medio de la población. La línea superior representa la probabilidad de ir al cine según el estatus socioeconómico para un perfil tipo: ser mujer joven (30 años) con titulación universitaria. Este perfil se corresponde con el grupo sociodemográfico en el que la asistencia al cine es más frecuente, a partir de los resultados anteriores. La probabilidad de que una mujer de 30 años con titulación universitaria vaya al cine varía del $57 \%$ entre las que tienen un estatus socioeconómico bajo al $80 \%$ entre las que tienen un estatus socioeconómico alto. Para un individuo medio de la población, la probabilidad varía del $24 \%$ al $49 \%$. En este caso vemos que las características sociodemográficas son más importantes que el estatus para explicar la asistencia al cine, porque incluso para el individuo medio de mayor estatus la probabilidad de asistir al cine es inferior que la probabilidad de asistir al cine para una mujer de 30 años con titulación universitaria y con la menor puntuación de estatus.

Figura 2. Probabilidad de ir al teatro para la media (línea inferior) y para una mujer de 50 años con título universitario (línea superior) según el estatus socioeconómic.

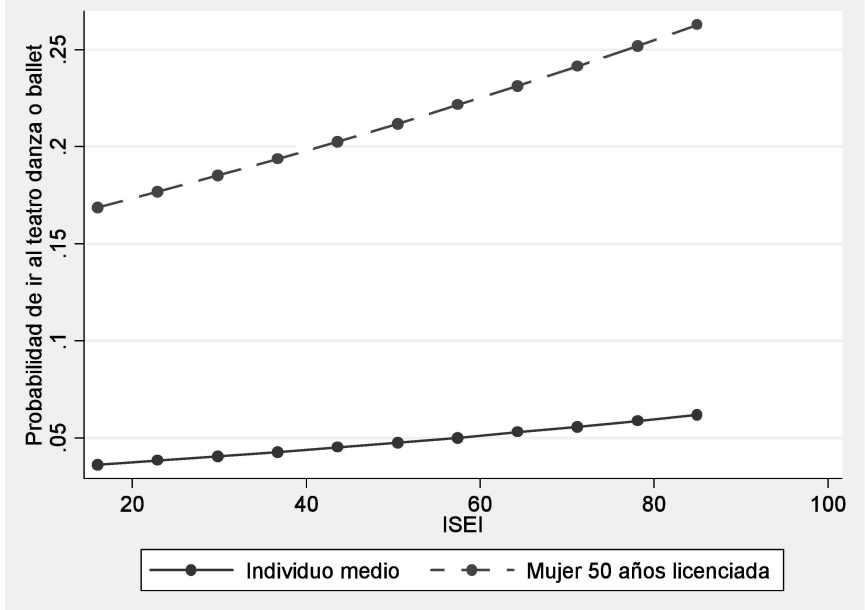

Fuente: Encuesta de Empleo del Tiempo 2002-2003 (INE) y elaboración propia. 
En la figura 2 simulamos esta vez, la probabilidad de haber ido al teatro, la danza o el ballet a medida que aumenta el estatus de los individuos. La línea inferior representa de qué forma aumenta la probabilidad de ir al teatro, la danza o el ballet a medida que aumenta el estatus socioeconómico para un individuo medio de la población. La línea superior representa la probabilidad de asistir a dicho evento según el estatus socioeconómico para un perfil tipo: ser mujer adulta (50 años) con titulación universitaria. Este perfil se corresponde con el grupo sociodemográfico en el que la asistencia al teatro, la danza o el ballet es más frecuente, a partir de los resultados de la regresión logística. La probabilidad de que una mujer de 50 años con titulación universitaria vaya al cine varía del 17\% entre las que tienen un estatus socioeconómico bajo al $26 \%$ entre las que tienen un estatus socioeconómico alto. Para un individuo medio de la población, la probabilidad varía del $3 \%$ al $6 \%$. En este caso vemos también que las características sociodemográficas son más importantes que el estatus para explicar la asistencia al teatro, la danza o el ballet, porque incluso para el individuo medio de mayor estatus la probabilidad de asistir al teatro, la danza o el ballet es inferior que la probabilidad de asistir al teatro, la danza o el ballet para una mujer de 50 años con titulación universitaria con el estatus más bajo.

Figura 3. Probabilidad de ir conciertos de música para la media (línea inferior) y para una persona de 30 años, soltera y con título universitario (línea superior) según el estatus socioeconómico

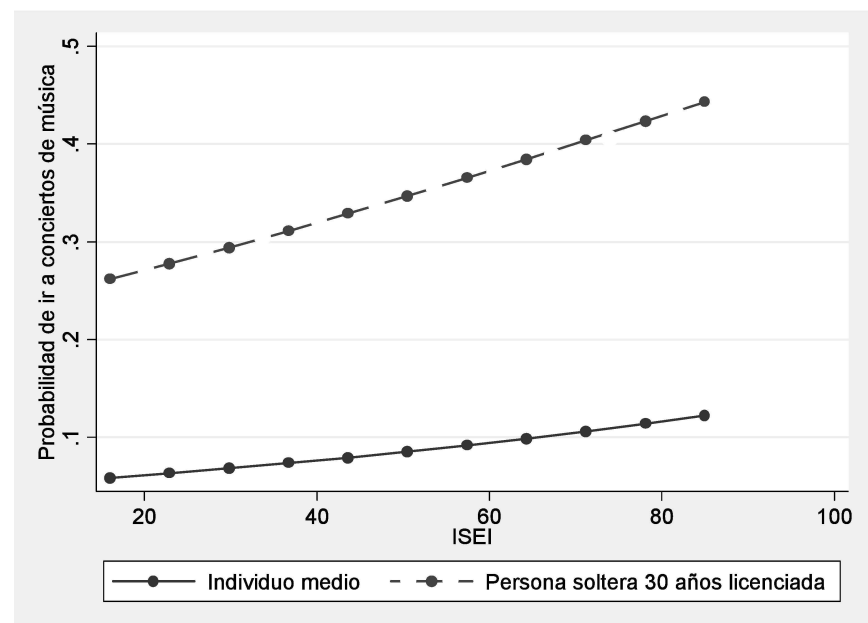

Fuente: Encuesta de Empleo del Tiempo 2002-2003 (INE) y elaboración propia.

En la figura 3 simulamos la probabilidad de haber ido a conciertos de música en los últimos 12 meses para un individuo medio de la población española (línea inferior), y para una persona de 30 años, soltera y con título universitario (línea superior) según su nivel de estatus. Este perfil se corresponde con el grupo 
sociodemográfico en el que la asistencia a conciertos de música es más frecuente, a partir de los resultados de la regresión logística. La probabilidad de que una persona soltera de 30 años con titulación universitaria vaya a conciertos de música varía del $26 \%$ entre las que tienen un estatus socioeconómico bajo, al $44 \%$ entre las que tienen un estatus socioeconómico alto. Para un individuo medio de la población, la probabilidad varía del $6 \%$ al $12 \%$. En este caso vemos una vez más, que las características sociodemográficas son más importantes que el estatus para explicar la asistencia a conciertos de música, porque incluso para el individuo medio de mayor estatus la probabilidad de asistir a conciertos de música es inferior que la probabilidad de asistir a conciertos de música para una persona soltera de 30 años con titulación universitaria con el estatus más bajo.

Figura 4. Probabilidad de ir a monumentos histórico-artísticos para la media (línea inferior) y para una persona de 50 años, soltera y con título universitario (línea superior) según el estatus socioeconómico

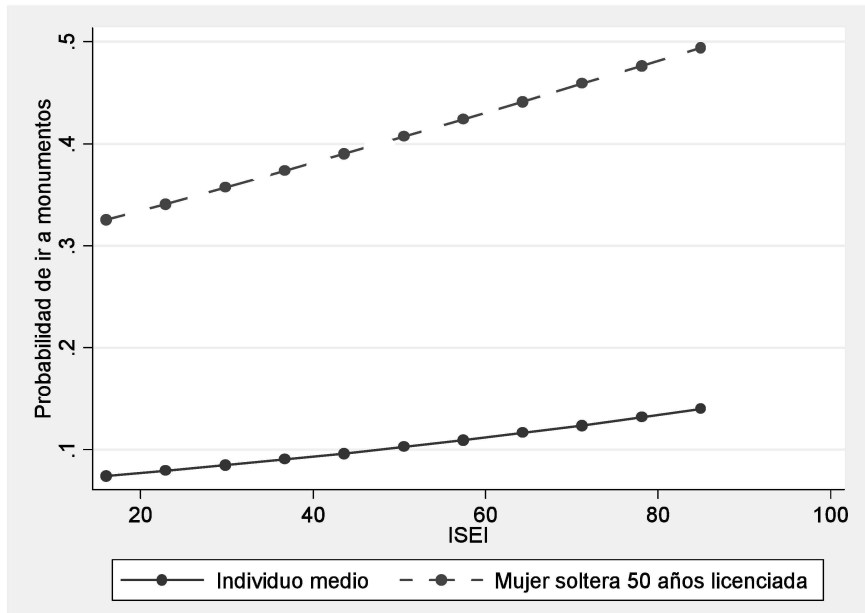

Fuente: Encuesta de Empleo del Tiempo 2002-2003 (INE) y elaboración propia.

En la figura 4, aparecen en esta ocasión la probabilidad de asistir a monumentos histórico-artísticos. Como en las anteriores figuras, la línea inferior representa la probabilidad de haber ido a monumentos histórico-artísticos en los últimos 12 meses para un individuo medio de la población española, mientras que la línea superior representa la misma probabilidad para una persona de 50 años, soltera y con título universitario según su nivel de estatus. Este perfil se corresponde, de nuevo, con el grupo sociodemográfico en el que la asistencia a monumentos histórico-artísticos es más frecuente, a partir de los resultados de la regresión logística. La probabilidad de que una persona soltera de 50 años con titulación universitaria vaya a monumentos histórico-artísticos varía del 32\% en- 
tre las que tienen un estatus socioeconómico bajo al $49 \%$ entre las que tienen un estatus socioeconómico alto. Para un individuo medio de la población, la probabilidad varía del 7\% al 14\%. Una vez más, vemos que las características sociodemográficas son más importantes que el estatus para explicar la visita a monumentos histórico-artísticos, porque incluso para el individuo medio de mayor estatus socioeconómico la probabilidad de visitar monumentos histórico-artísticos es inferior que la probabilidad de visitar monumentos histórico-artísticos para una persona soltera de 50 años con titulación universitaria y con la puntuación de estatus socioeconómico más bajo.

Figura 5. Probabilidad de ir museos y exposiciones de arte para la media (línea azul) y para una mujer de 50 años, soltera y con título universitario (línea superior) según el estatus socioeconómico

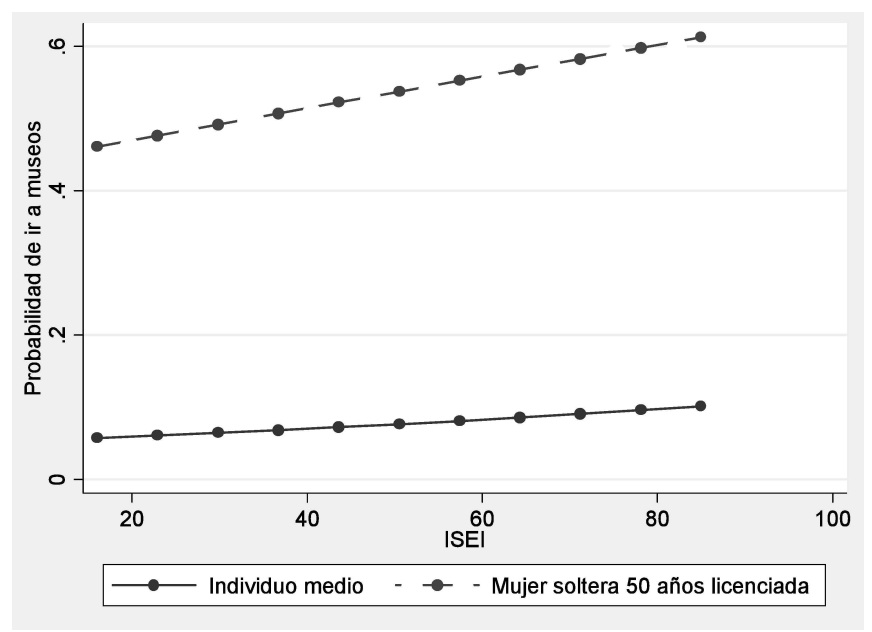

Fuente: Encuesta de Empleo del Tiempo 2002-2003 (INE) y elaboración propia.

Finalmente en la figura 5, aparece la probabilidad de asistir a museos y exposiciones de arte. La línea inferior en esta ocasión, representa la probabilidad de haber ido a museos y exposiciones de arte en los últimos 12 meses para un individuo medio de la población española, mientras que la línea superior representa la misma probabilidad para una mujer de 50 años, soltera y con título universitario según su nivel de estatus. Este perfil se corresponde con el grupo sociodemográfico en el que la asistencia a museos y exposiciones de arte es más frecuente, a partir de los resultados de la tabla 4. La probabilidad de que una mujer soltera de 50 años con titulación universitaria vaya a museos y exposiciones de arte varía del $46 \%$ entre las que tienen un estatus socioeconómico bajo al $61 \%$ entre las que tienen un estatus socioeconómico alto. Para un individuo medio de la población, la probabilidad varía del $5 \%$ al $10 \%$. En este último caso vemos otra vez que las características sociodemográficas son más importantes que el es- 
tatus para explicar la visita a museos y exposiciones de arte. Incluso para el individuo medio de mayor estatus la probabilidad de visitar museos y exposiciones de arte es inferior que la probabilidad de visitar museos y exposiciones de arte para una mujer soltera de 50 años con titulación universitaria con el menor nivel de estatus.

En resumen, tener un mayor estatus socioeconómico es una característica de los individuos que nos permiten predecir una mayor participación en eventos de carácter cultural como ir al cine, al teatro o a museos. Pero por encima del estatus, la configuración de determinadas características sociodemográficas nos ayudan a predecir mejor la probabilidad de participar en dichos eventos. En este sentido, y como afirman algunos autores (Ganzeboom, 1982; Kraaykamp y Dijkstra, 1999), la mayor capacidad de procesamiento de la información que confiere el hecho de tener mayores niveles educativos provee de mayor capacidad para entender prácticas artístico-culturales sofisticadas, como son las de alta cultura.

Pertenecer a la clase de servicio en lugar de pertenecer a la pequeña burguesía, a la clase obrera tradicional o a la clase de obreros cualificados, aparece como una característica significativa a la hora de predecir el conjunto de prácticas culturales analizadas. No obstante, este dato no puede llevarnos a un error en la interpretación del modelo. Si estos comportamientos se diesen exclusivamente en la clase de servicio, las diferencias significativas hubiesen aparecido en todas y cada una de las comparaciones con el resto de clases sociales. Como hemos podido observar, esto no ha sucedido. Sin embargo, un modelo de estratificación social puramente jerárquico, como es el estatus, funciona como variable predictora en todos los consumos culturales. Por consiguiente, creemos que la utilización de escalas métricas de estratificación social, como son las de prestigio o estatus social, en lugar de esquemas de clases sociales, conforma una estrategia metodológica más óptima para predecir los consumos y prácticas culturales ${ }^{4}$.

\footnotetext{
${ }^{4}$ La relevancia empírica de la distinción entre clase y estatus social en el estudio de la estratificación del consumo cultural tiene, sin duda, una importancia capital en la tradición sociológica reciente (Chan y Goldthorpe, 2007a). Sin embargo, adentrarnos ahora en las implicaciones teóricas que estos resultados han sacado a la luz supone un ejercicio que supera las intenciones de este artículo. El motivo de incluir ambos modos de estratificación, clase social y estatus social, reside en la necesidad de controlar de un modo fehaciente que la práctica de dichas actividades culturales está, de algún u otro modo, influenciada por características de estratificación social en los individuos, ceteris paribus. Para un mayor detalle de dicha distinción conceptual y su relevancia empírica en campos como el consumo cultural y otros, véase Chan y Goldthorpe (2007a). Por consiguiente, consideraremos que, ya sea a través de la clase o el estatus social, lo importante del resultado de nuestros análisis de regresión logística ha sido la prevalencia de un mayor consumo cultural «distinguido» entre los estratos mejor posicionados.
} 


\subsection{La posición de las clases sociales en el espacio de los estilos de vida y consumo cultural}

De los anteriores análisis de regresión logística hemos concluido que, la asistencia a eventos considerados de haut culture, highbrow o alta cultura es más probable entre aquellos individuos mejor posicionados en la escala social. En otras palabras, tener un estatus socioeconómico alto (ya sea medido a través del ISEI, o al comparar la clase de servicio I con la clase de obreros no cualificados, por ejemplo), aumenta la probabilidad de asistir al teatro, al ballet o a museos y exposiciones. También hemos observado como otras características sociodemográficas como la edad, la educación, los ingresos o el sexo influyen de manera importante para predecir la asistencia a dichos eventos.

Ahora bien, y como análisis complementario que refuerce dicho argumento, se nos antojaría interesante explorar ahora qué tipo de estilos de vida se asocian a cada una de las clases sociales. Es decir, sería conveniente ir más allá del consumo específico de la alta cultura y adentrarnos en el campo de la cultura considerada en términos generales. Estimarla en su sentido antropológico, a través de los estilos de vida.

Esta vez no vamos a calcular la probabilidad de que ocurra o no un suceso en concreto - como ir al cine o a los museos- sino que vamos a examinar qué tipo de consumo y, por tanto, de estilo de vida, está más relacionado con cada clase social. Para ello, utilizaremos un análisis de correspondencias múltiples que nos ayudará a aclarar si los diferentes estilos de música, de programas de televisión y de ropa están asociados entre sí, y, a su vez, a las diferentes clases sociales $^{5}$. El motivo es que si queremos ir más allá del modelo clásico de causali-

\footnotetext{
${ }^{5} \mathrm{El}$ esquema de clases que vamos a utilizar en este análisis es la versión mixta de la tabla A1 (ver anexo). Después de comenzar nuestro análisis de correspondencias hemos ido reduciendo los números de clases de las 11 iniciales a las 7 actuales guiados por las semejanzas y diferencias entre las clases más próximas. Es por ello, que la clase de rutina no manual aparece desagregada, mientras que la clase de servicio I y II, y los pequeños propietarios IVa, IVb y IVc aparecen agregados en «I y II» y «IV». Una de las distinciones de clase que marcan el análisis de Bourdieu (2006) y que omiten Erikson, Goldthorpe y Portocarero (1979) en la elaboración de su esquema, es la diferencia de clases entre grandes propietarios y profesionales. Son dos los motivos básicos para omitir dicha distinción (Marshall, Swift y Roberts, 2002: 25). En primer lugar, las muestras aleatorias de ámbitos nacionales no permiten captar la población de los grandes propietarios, que no llegan a sumar ni siquiera un $10 \%$ de la clase de servicio I (Erikson y Goldthorpe, 1992: 40). Debido a esta poderosa razón, nuestro propósito se centra en la explicación de grandes regularidades estadísticas, es decir, lo que buscamos son argumentos razonables que sirvan para dar cuenta de cómo ciertas prácticas culturales recurrentes están asociadas a determinados grupos. Por otro lado, estos grandes propietarios, en su mayor parte dueños de talleres, hoteles y empresas del transporte, también realizan funciones «manageriales», así como los managers también suelen disfrutar de participaciones en las empresas que gestionan. Managers y grandes propietarios comparten así, funciones ocupacionales y esquemas cognitivos similares (Beltrán, 2003). No obstante, la distinción con el resto de profesionales requeriría de un mayor esfuerzo teórico, el cuál, supera las intenciones de este artículo (para más información sobre nuevos modos de ajustar la clase de servicio del esquema EGP, véase Güveli, 2006).
}

EMPIRIA. Revista de Metodología de Ciencias Sociales. N. ${ }^{\circ}$ 22, julio-diciembre, 2011, pp. 141-172. ISSN: $1139-5737$ 
dad - variables explicativa que influyen sobre una variable explicada -, hemos de seleccionar un técnica que dé cuenta dé la totalidad de las relaciones que guardan las distintas categorías de las variables (Bourdieu, 2006: 123). El análisis factorial de correspondencias múltiples cumple dicho objetivo pues con él podemos configurar un mapa en el que se representan visualmente las asociaciones entre las categorías de un conjunto de variables. Como señalaba Bourdieu a este respecto, este tipo de análisis pretende mostrar «una idea tan exacta como sea posible del modelo teórico» (Bourdieu, 2006: 123) en este caso el argumento de la homología, y de este modo, superponer, por un lado, la distribución de las clases sociales, y, por el otro, a modo de «lámina transparente», el espacio de los estilos de vida. El producto de la conjunción de ambas «láminas transparentes» es lo que el sociólogo francés denomina como el tercer esquema del análisis, es decir, el habitus de cada clase. Para nuestro análisis utilizaremos esta vez la Encuesta de Estructura y Clases Sociales (CIS, 2006; n= 6.623 casos válidos tras eliminar los casos perdidos). En la figura 6 se muestran gráficamente el resultado de nuestro análisis de correspondencias múltiples.

En el cuadrante 1 de la figura 6, con puntuaciones positivas en ambos ejes, apreciamos que las clases manuales (VI y VII) se vinculan con los programas de televisión de carácter popular, como las telenovelas, los concursos o los programas de prensa rosa. También estas clases se relacionan con el consumo de música de producción nacional (flamenco, canción española, etc.) y la ropa de corte normal y a buen precio. En el cuadrante inverso del gráfico, el cuadrante 3, donde se sitúan las categorías con puntuaciones negativas en ambos ejes, nos encontramos las clases no manuales con mayores niveles de formación (clases I, II, y IIIa). Ésta es para Bourdieu la oposición principal en su análisis de la homología de las prácticas culturales, entre aquellos consumos considerados vulgares, por parte de individuos que se encuentran desprovistos de capital económico y cultural, y aquellos considerados distinguidos, de individuos que están mejor provistos de ingresos y nivel educativo (Bourdieu, 2006: 175). Asociadas a estas clases no manuales con formación (I, II, y IIIa), nos encontramos también programas de televisión de carácter educativo, como los documentales, y géneros musicales más «eruditos», si se me permite la expresión, como el jazz, el blues, el soul y el folk. Según Ariño et al. (2006), el hecho de que el consumo de estos géneros esté asociado de algún modo a la alta cultura es debido a que sus consumidores «muestran una apertura mayor [...] a aquellas prácticas de la cultura popular que han sido creadas por grupos marginales (negros, jóvenes, rurales aislados) como el blues, el jazz, etc. ${ }^{\dagger} \gg(2006: 37)$.

Frente a estos dos cuadrantes antagónicos, nos encontramos los cuadrantes donde situaríamos otras clases intermedias del esquema EGP, a saber, la clase de

\footnotetext{
${ }^{6}$ Los autores se refieren al consumo de estos géneros dentro del argumento o paradigma de la omnivoridad, que ya analizaremos más adelante, tratando de explicar que la mayor apertura de los omnívoros culturales a diferentes géneros como el blues o el jazz no es indiscriminada, sino que la selección de éstos se rige a través de un «esteticismo romántico» fruto de una modalidad de consumo reflexiva, intelectual y estilizada de la cultura popular.
} 
Figura 6. Análisis de correspondencias sobre el espacio de las clases sociales y el espacio de los Estilos de vida

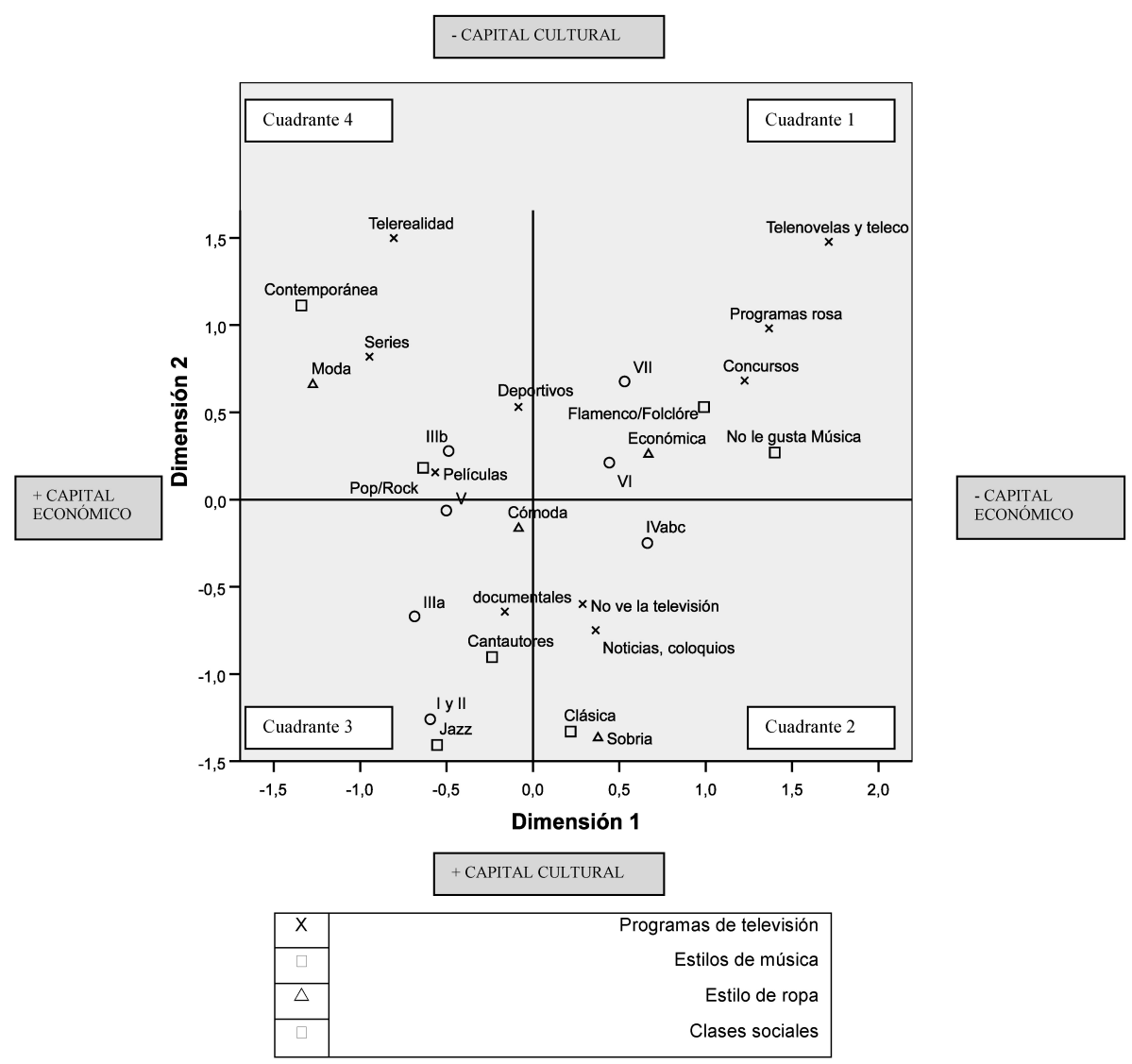

Fuente: Encuesta de Estructura y Clases Sociales, 2006 (Estudio 2634, CIS) y elaboración propia $\mathrm{n}=6623$

trabajadores no manuales de rango bajo (IIIb) en el cuadrante 4, y la clase de pequeños propietarios (IV) en el cuadrante 2. Ésta última clase social supone un reto desde el punto de vista sociológico puesto que conforma un grupo muy heterogéneo en cuanto a su «dispersión económica y cultural» (Bourdieu, 2006: 126). A pesar de ello, podemos encontrar ciertas diferencias en los estilos de vida de ambos cuadrantes. Si bien la clase de pequeños propietarios prefiere no ver la televisión o la puede ver en busca de información de interés general, como son las noticias o las tertulias, la clase IIIb está asociada a programas de contenido 
más exclusivos del medio televisivo y que, además, exigen de un consumo más constante. Éste es el caso de las series o los programas de telerrealidad como Gran Hermano. Aquí las diferencias en el uso del tiempo aparecen como cardinales a la hora de distinguir el consumo de televisión en ambas clases sociales. Bourdieu afirmaba en este sentido que las clases dominantes con propiedades tenían con frecuencia más edad ${ }^{7}$ y disponían de poco tiempo libre, al contrario de las clases intermedias, usualmente sin propiedades $-8 \mathrm{y}$ «dotadas sobre todo de capital escolar y de tiempo libre» (Bourdieu, 2006: 120).

Por otro lado, los pequeños propietarios están más cerca de preferir una ropa sobria y formal, mientras que los empleados no manuales de rango bajo prefieren la ropa de moda, chic o rebuscada. Estos antagonismos también parecen reflejarse en el plano de las preferencias musicales, donde la clase IV se sitúa cerca de gustos más clásicos y tradicionales (clásica, flamenco...) mientras que la clase IIIb prefiere músicas modernas y de influencia internacional como la electrónica, el hip-hop, el rock o el pop. Esta diferencia en las preferencias musicales bien podría correlacionarse también con las diferencias de la edad media de ambas clases. De hecho, Ariño et al. (2006) llegan a conclusiones muy parecidas al analizar los gustos culturales de las diferentes generaciones. Los autores afirman que aquellos que tienen gustos denominados etno-rock, aumentan con la juventud de los entrevistados, exactamente «la misma evolución generacional que el referido a la cultura pop-show» (2006: 292).

Del análisis de correspondencias que acabamos de realizar podemos obtener varias conclusiones:

Existen prácticas culturales y estilos de vida fuertemente relacionadas con ciertas clases en concreto. Las clases no manuales con mayor capital cultural y económico (a saber, clases de servicio I y II) tienen como música favorita al jazz, el soul, el blues, o la canción protesta en mayor medida que el resto de clases sociales. Además, tienen como programas de televisión preferidos los documentales y los programas educativos. Por otro lado, la clase manual sin formación y con menores ingresos (VII) está más asociada a gustos populares y de consumo masivo como los programas de televisión de prensa rosa, los concursos y las telenovelas, mientras que el plano de la música, se inclinan por estilos nacionales como el flamenco y la canción española.

En conjunto pueden clasificarse las prácticas culturales y estilos de vida en dos grupos disímiles: unos con una fuerte asociación a unas clases sociales particulares y otras con una asociación más débil (estas son las que quedan obvia-

${ }^{7} \mathrm{Al}$ contrastar la edad media de ambas clases, se observa que la clase de trabajadores no manuales de rango bajo presenta la edad media más baja de todas, 40,6 años, mientras que la clase de pequeños propietarios la más alta, 53,1 .

${ }^{8}$ Según la Encuesta de Estructura y Clases Sociales (CIS, 2006) que hemos utilizado, en el caso de España también se confirmaría el hecho de que la clase IIIb de asalariados no manuales de rango bajo tienen menos viviendas en propiedad que la de pequeños propietarios (un 80,3\% frente a un $90,1 \%$ ). Ambos son los porcentajes más bajos y más altos respectivamente de toda la estructura de clases.

EMPIRIA. Revista de Metodología de Ciencias Sociales. N. ${ }^{\circ} 22$, julio-diciembre, 2011, pp. 141-172. ISSN: $1139-5737$ 
mente ubicadas más al centro de los dos ejes de nuestro análisis, puesto que son prácticas más comunes a la población en su conjunto). Prácticas como el ver películas, programas deportivos, o vestir ropa cómoda, cuyas puntuaciones en ambas dimensiones no son altas, podríamos considerarlas comunes a todas las clases sociales. Del mismo modo, existen clases sociales ubicadas también alrededor del centro, lo que nos indica una cierta heterogeneidad de sus prácticas culturales y estilos de vida, como la clase de técnicos y supervisores manuales $(\mathrm{V})^{9}$. No obstante no habría que desdeñar las diferencias entre la clase de trabajadores no manuales de rango bajo (IIIb), y la clase de pequeños propietarios (IV). Su ubicación en cuadrantes simétricamente inversos nos permite asociarles ciertos consumos y estilos de vida contrapuestos, pero hay que tener en cuenta que esta oposición no es tan fuerte como la que tienen las clases de servicio I y II frente a la de clase obreros no cualificados (VII). Por consiguiente, este análisis refuerza la tesis de una estratificación del consumo cultural, que ya habíamos comprobado en el anterior análisis de regresión logística, frente a la tesis de la individualización, aunque no encuentra evidencias decisivas de la validez del argumento de la homología, tal y como averiguó Bourdieu. Al contrario que Bourdieu que encontró estilos de vida diferenciados para cada una de las clases sociales, nosotros sólo hemos podido encontrar evidencias importantes para los estratos más alejados de la escala social.

Por último, las dimensiones que aparecen en el gráfico se corresponden con dos ejes que distribuyen las clases sociales en función de su capital económico y de su capital cultural, como ha quedado señalado en el esquema de correspondencias (figura 6).

En resumen, el argumento de la homología que enfrentaba los gustos culturales asociados a las diferentes clases sociales, parece aplicarse de manera sólida en las diferencias entre las clases I y II, por un lado, y, la clase VII, por otro. Puesto que existe cierta homogeneidad en los gustos culturales asociadas a estas clases sociales, puede pensarse, como hace Bourdieu, que todos sus miembros comparten un esquema de percepción común o habitus (Bourdieu, 2006: 100). En cambio, establecer dicho habitus de clase objetiva para el resto de clases sociales se presenta algo más difícil debido a la mayor heterogeneidad en las prácticas de clases como la de los supervisores o la de los trabajadores cualificados.

El problema que plantea este análisis no reside en la validez de sus resultados sino en la misma formulación de las preguntas sobre estilos de vida utilizadas en la Encuesta de Estructura y Clase Social (CIS, 2006). Éstas están diseñadas para recoger las preferencias en el gusto pero no así el total de prácticas y consumos culturales que realizan los individuos. Al contemplar la totalidad de géneros que se consumen en un ámbito concreto de la actividad cultural, podre-

\footnotetext{
${ }^{9}$ Bien es cierto que este efecto también pudiese deberse a la masa de cada una de las clases sociales, es decir, al peso muestral pero, indudablemente, la contribución a cada uno de los ejes nos orienta adecuadamente sobre sus relaciones con las variables culturales.
} 
mos comprobar así la potencia heurística del argumento de la omnivoridad utilizando, no ya los gustos y estilos de vida como predictores de la estratificación social, sino, en su lugar, las modalidades de consumo cultural.

A continuación presentaremos los resultados de un análisis que, gracias al diseño propio de la encuesta, la Encuesta de Hábitos y Prácticas Culturales (Ministerio de Cultura, 2007), si que permite recoger el total de géneros musicales que escucha el entrevistado sin establecer una única categoría preferente, dando cuenta de la complejidad de los modos de consumo cultural en la sociedad española contemporánea.

\subsection{La omnivoridad cultural en el ámbito de la música}

Como hemos visto en el apartado anterior, existen diferencias persistentes en las estructuras del gusto y las prácticas culturales, y mientras «la clase social sigue contando como factor explicativo, las diferencias, crecientes, demandan la toma en consideración de otros factores» (Ariño et al., 2006: 36) como el modo de consumo cultural y otras características explicativas como «la educación, el sexo o la edad» (Wilensky, 1964: 195).

De hecho, existen multitud de autores (Wilensky, 1964; DiMaggio y Useem, 1978; DiMaggio, 1987; Peterson y Simkus, 1992; Peterson y Kern, 1996; LópezSintas y García-Álvarez, 2002; Chan y Goldthorpe, 2005, 2006, 2007a, 2007b, 2007c; Torche, 2007) que han comprobado que las diferencias en las prácticas culturales de los diferentes estratos sociales, no se establecen en aquello que se consume, sino en «la modalidad de consumo» (Ariño et al., 2006: 37). Dicho de otro modo, los estratos sociales más altos tienen la capacidad de apreciar todos los estilos y prácticas culturales, abriéndose a consumos más diversos, mientras que los estratos sociales más bajos tienden a consumir un abanico menor de productos y servicios culturales. A este enfoque lo hemos denominado argumento de la omnivoridad en el consumo cultural. Para verificar la validez de esta teoría, la comunidad científica ha utilizado diferentes técnicas estadísticas, todas ellas con el mismo objetivo: comprobar, frente a la vieja idea de un consumidor snob y exclusivo de alta cultura, la existencia de un perfil de consumidor cultural capaz de acaparar no sólo géneros y prácticas de alta cultura sino también de media y baja. DiMaggio $(1978 ; 1987)$ comprobó a través de análisis descriptivos bivariados como las personas con mayor estatus socioeconómico, medido a través de su ocupación y de su nivel educativo, consumían un mayor rango de géneros de actividad cultural. Peterson y Kern (1992) utilizaron un análisis de regresión lineal para comparar cómo aquellos individuos que tenían como género musical preferente la ópera o la música clásica, también consumían géneros «middlebrow» $\mathrm{y}$ «lowbrow» (media y baja cultura) en mayor proporción que el resto.

De un modo menos causal, en nuestro país Ariño et al. (2006) utilizó el análisis factorial para obtener perfiles de consumo cultural estratificado como ya 
hizo Katz-Gerro (2002). A pesar de encontrar un gran número de perfiles en cuanto a gustos y prácticas culturales, las evidencias sobre un perfil de consumidor cultivado omnívoro tal y como hizo Peterson y Kern (1992) fueron bastante débiles. Por otro lado, Torche (2007) utilizó un modelo de regresión logística ordinal para captar la omnivoridad en la lectura, de tal modo que, la variable dependiente va de (0) leer un solo género, (1) leer dos géneros y (2) leer tres o más géneros literarios (2007: 87). Este método, a pesar de no presentar grandes problemas en cuanto a la validez de sus resultados, presenta a nuestro parecer ciertas deficiencias. La investigadora establece que todo aquel que consumo más de tres géneros presenta un consumo omnívoro en la lectura. Este método no permite que sean los datos los que saquen a la luz las estructuras de consumo a través de las respuestas de los encuestados sino que, en contra de la metodología usual en la investigación sociológica del consumo cultural, es la investigadora quién establece cuál es el patrón de consumo que podríamos catalogar como omnívoro.

En los últimos años ha habido una importante oleada de producción científica alrededor del estudio del consumo cultural omnívoro utilizando la técnica del Latent Class Analysis (Lazarsfeld y Henry, 1968) o Análisis de Clases Latentes (LCA a partir de ahora). Básicamente, el LCA es una técnica que permite la clasificación de los individuos a las diferentes clases o «clusters» a través de una aproximación probabilística ${ }^{10}$. A pesar de la ingente cantidad de estudios en la materia y del consenso en cuanto al uso de esta técnica (Van Rees, Vermunt y Verboord, 1999; López-Sintas y García-Álvarez, 2002; López-Sintas, García-Álvarez y Filimon, 2008; Zavisca, 2005; Chan y Goldthorpe, 2005, 2006, 2007a, 2007b, 2007c; entre otros), el estudio del «Omnivorismo» $\mathrm{u}$ «Omnivoridad cultural» por estos autores ha levantado ciertas suspicacias sobre su validez de constructo. Estas críticas apuntan tanto a la técnica utilizada (Wuggenig, 2007) como al modo de recogida de datos y las medidas utilizadas para calibrar el consumo cultural (Lahire, 2008).

Nosotros hemos decidido utilizar el LCA porque consideramos que es la técnica más óptima para captar la modalidad de consumo musical, es decir, la capacidad de consumir o no un amplio abanico de géneros musicales. Desde el punto de vista teórico, esta técnica nos va a permitir captar modos de consumo cultural no preferentes, lo cuál nos sirve de gran utilidad para observar las constelaciones de gustos culturales según las características sociales de los individuos. En efecto, la estructura loglinear del LCA nos permite «analizar datos ca-

\footnotetext{
${ }^{10}$ A pesar de sus semejanzas con otros tipos de análisis de clasificación considerados de poca robustez o fuzzy clustering, el LCA presenta una serie de características propias que lo han hecho más y más popular en los últimos años (Vermunt y Magidson, 2006a). Según Vermunt y Magidson, las probabilidades que tiene un individuo de pertenecer a una clase son directamente computadas de los parámetros del modelo estimado y sus puntuaciones observadas. En otras palabras, el LCA permite clasificar a los individuos en una clase a través de un método exhaustivo y excluyente, lo cual no es posible a través de otras técnicas de fuzzy clustering estándar (Vermunt y Magidson, 2006b: 2). Es lo que se conoce como método de asignación modal..
} 
tegóricos, que no requieren distinción alguna entre variables dependientes e independientes y que se centra concretamente en las estructuras de asociación e interacción» (Goldthorpe, 2010: 251).

Al contrario de lo que hacen Chan y Goldthorpe (2007c) nosotros hemos decidido omitir la asistencia a música en directo y, por otro lado, hemos preferido no dicotomizar el abanico de géneros musicales entre alta cultura y cultura popular como hacen los autores. De este modo, vamos a ganar una mayor riqueza descriptiva de las preferencias musicales a través de un mayor número de géneros, algunos de ellos, endémicos de nuestro país -como es el caso del flamenco-.

A continuación, presentamos los resultados de nuestro LCA con el consumo de diferentes géneros musicales y un conjunto de covariables sociodemográfi$\operatorname{cas}^{11}$. La introducción de covariables en el modelo nos permitirá predecir la pertenencia de los diferentes grupos de individuos a las diferentes clases latentes (Dayton y Macready, 1988; Hagenaars y McCutcheon, 2002). Estas covariables son: género; cohortes de edad de 10 en 10 años; años de estudios que van de los 0 años para la población sin estudios a los 17 años para la población con estudios de licenciatura universitaria y superior; estado civil, que incluye aquella población con hijos menores de edad a su cargo o con hijos mayores de edad, ya sean casados, solteros o en pareja. Las variables utilizadas corresponden a las preguntas incluidas en la Encuesta de Hábitos y Prácticas Culturales (Ministerio de Cultura, 2007; $\mathrm{n}=14.241$ casos válidos, una vez omitidos los valores perdidos).

Tabla 2. Modelos estimados de clases latentes

\begin{tabular}{cccccccc}
\hline $\begin{array}{c}\text { Forma del } \\
\text { Modelo }\end{array}$ & $\mathbf{X}^{\mathbf{2}}$ & $\begin{array}{c}\% \text { de } \mathbf{X}^{2} \\
\text { reducido }\end{array}$ & df & AIC & $\begin{array}{c}\% \text { de AIC } \\
\text { reducido }\end{array}$ & BIC & $\begin{array}{c}\% \text { de BIC } \\
\text { reducido }\end{array}$ \\
\hline 2 clases & 62950052 & 0 & 8155 & 149177,4 & 0 & 149449,7 & 0 \\
\hline 3 clases & 2120011,8 & $-96,64$ & 8132 & 144930,7 & $-2,85$ & 145377 & $-2,73$ \\
\hline 4 clases & 1933094 & $-96,93$ & 8109 & 145077,9 & $-2,75$ & 145698,2 & $-2,51$ \\
\hline
\end{tabular}

Fuente: Encuesta de Hábitos y Prácticas Culturales 2006-2007 y elaboración propia.

La tabla 2 muestra los resultados de los modelos de LCA para estos datos que van de 2 hasta 4 clases latentes. Para comparar los ajustes del modelo hemos utilizado dos criterios de información estadística (AIC y BIC). Como estadístico

\footnotetext{
${ }^{11}$ No están incluidas ni la clase social ni el estatus socioeconómico. Al igual que en Ariño et al., (2006), las preguntas con las que construimos las clases sociales y las puntuaciones ISEI (a saber, ocupación laboral, situación sociolaboral y control en la supervisión de trabajadores) no fueron incluidas en el cuestionario realizado por el Ministerio de Cultura y la Sociedad General de Autores y Editores. Como hemos podido comprobar a través de todo el artículo, los años de educación nos puede servir de variable proxy de la estratificación social, es decir, el nivel educativo funciona como característica de estratificación social análoga a la clase social o el estatus socioeconómico.
} 
de ajuste global del modelo hemos utilizado el $X^{2}$ o Chi-Cuadrado. La casilla $d f$ recoge los grados de libertad de cada modelo. Basándonos tanto en el BIC como en el AIC (Zavisca, 2005: 1240), el modelo de 3 clases es el que mejor ajusta. Como se observa, el modelo de 4 clases reduce tanto el $A I C$ como el BIC en menor proporción que el modelo de 3 clases. Por consiguiente, se ha rechazado utilizar el modelo de 4 clases.

Para ilustrar claramente la estructura de asociaciones e interacciones entre géneros en cada una de las tres clases latentes del modelo, hemos diseñado la figura 7. El gráfico se lee del siguiente modo: La probabilidad de escuchar habitualmente música clásica es del 54\% para los miembros de la clase 3, 20\% para los miembros de la clase 1 y del $10 \%$ para los miembros de la clase 2 .

Figura 7. Probabilidades condicionales de asociación entre géneros musicales. Modelo de tres clases latentes

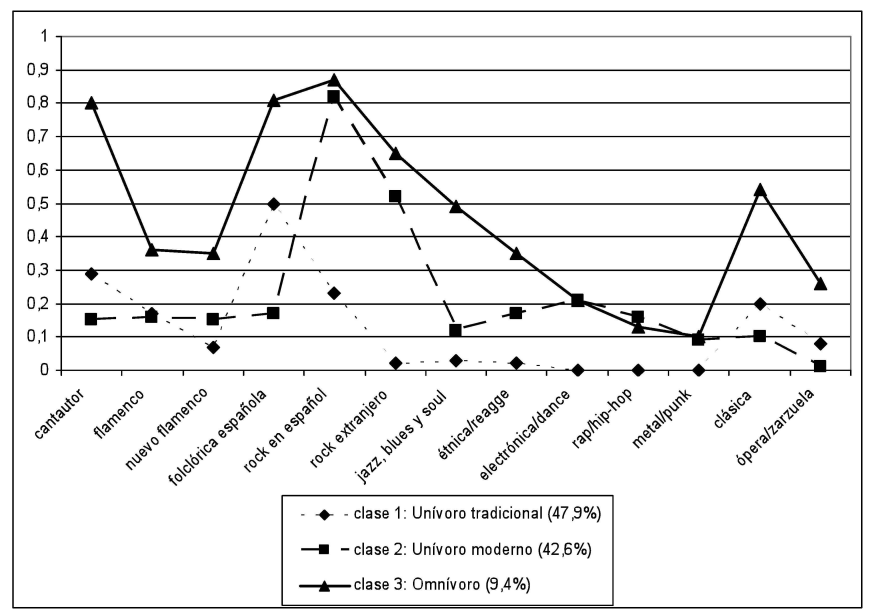

Fuente: Encuesta de Hábitos y Prácticas Culturales 2006-2007 y elaboración propia.

La clase 1 (a la cual pertenece un 47,9\% de los casos) acumula unas altas probabilidades de consumir géneros musicales de raíz española y latina como son la canción de cantautor o la canción melódica y folclórica española. Además, tiene unas puntuaciones moderadas en flamenco, música clásica y rock/pop en español, así como escasas o nulas probabilidades de escuchar el resto de géneros. De hecho, es la clase latente que presenta el patrón de consumo musical más débil o «inactivo» (Chan y Goldthorpe, 2007c), estando fundamentalmente ligados a géneros tradicionales y de raíces populares. Esta clase latente la hemos denominado consumo unívoro tradicional. La clase 2 (42,6\% de los casos) presenta niveles muy altos en consumos de géneros musicales de origen moderno como son el género rock/pop. Junto a la clase 3, la clase 2 es la que presenta más probabilidades de escuchar otros géneros de origen contemporáneo y ligados a la 
cultura urbana, como son la música electrónica o el rap/hip-hop. Además, es la clase que presenta menores probabilidades de escuchar géneros highbrow como la música clásica o la ópera/zarzuela. Esta segunda clase la hemos denominado consumo unívoro moderno. Por último, la clase 3 (9,4\% de los casos) muestra el patrón de consumo más ecléctico y variado de todos. No sólo es el que más consume músicas de alta cultura, sino también la que presenta mayores probabilidades de consumo en el resto de géneros. Es, en este sentido, la clase latente que presenta la mayor voracidad cultural de todas y por tanto, la omnivoridad más pura. La hemos denominado consumo omnívoro. En términos comparativos, la población que pertenece a la clase omnívora es inferior a la obtenida por Chan y Goldthorpe (2006: 4) para la sociedad británica (9,4\% frente a los 19,1\%).

El análisis de regresión logística multinomial que se presenta en la tabla 3 , muestra el efecto de cada una de las covariables sobre la probabilidad de pertenecer a la clase omnívoro y a la clase unívoro moderno frente a la probabilidad de pertenecer a la clase unívoro tradicional, según el conjunto de covariables independientes. Dicho con un ejemplo, la tabla 3 mostraría el efecto que tiene el hecho de ser mujer sobre la probabilidad de ser omnívoro frente a ser unívoro en un individuo.

Tabla 3. Análisis de regresión logística multinomial: tipos de consumidores de música como variable dependiente

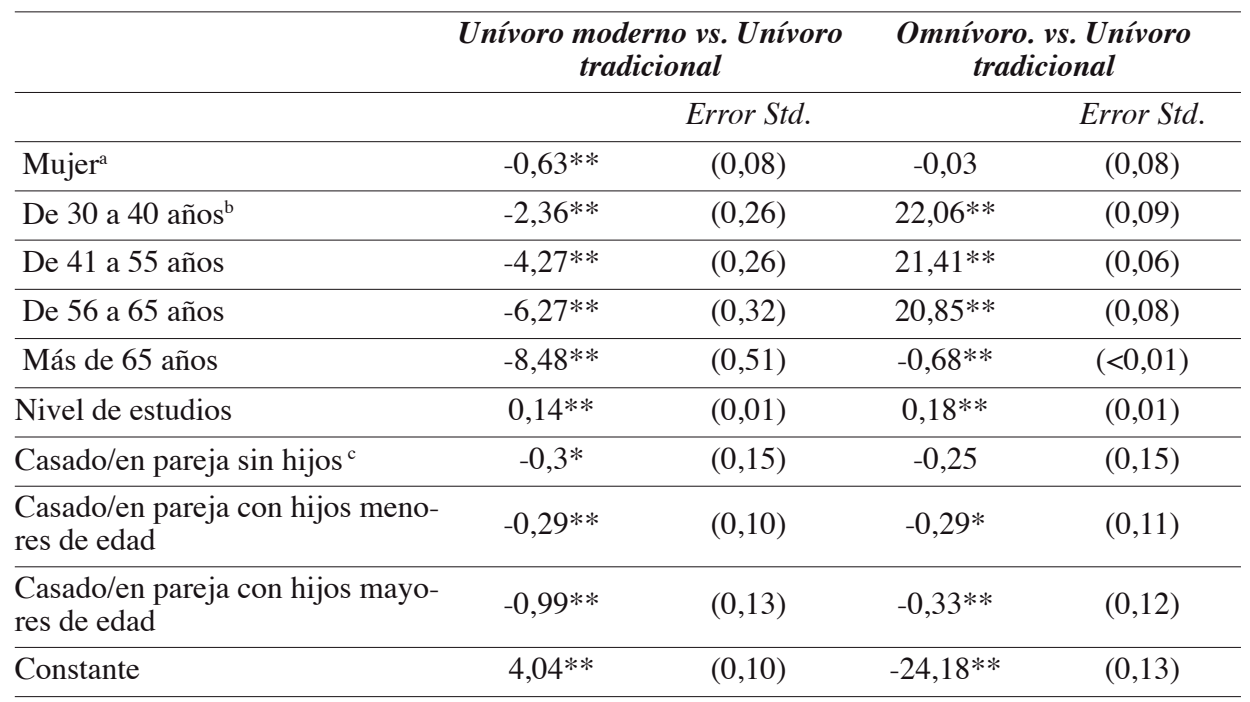

$* p<0,05 ; * * p<0,01$.

Fuente: Encuesta de Hábitos y Prácticas Culturales 2006-2007 y elaboración propia. $\mathrm{n}=14241$

${ }^{a}$ Hombre como categoría de referencia

${ }^{\mathrm{b}}$ de 18 a 29 años como categoría de referencia

${ }^{\mathrm{c}}$ soltero como categoría de referencia 
Figura 8. Probabilidad de pertenecer a cada una de las tres clases latentes según el nivel de estudios

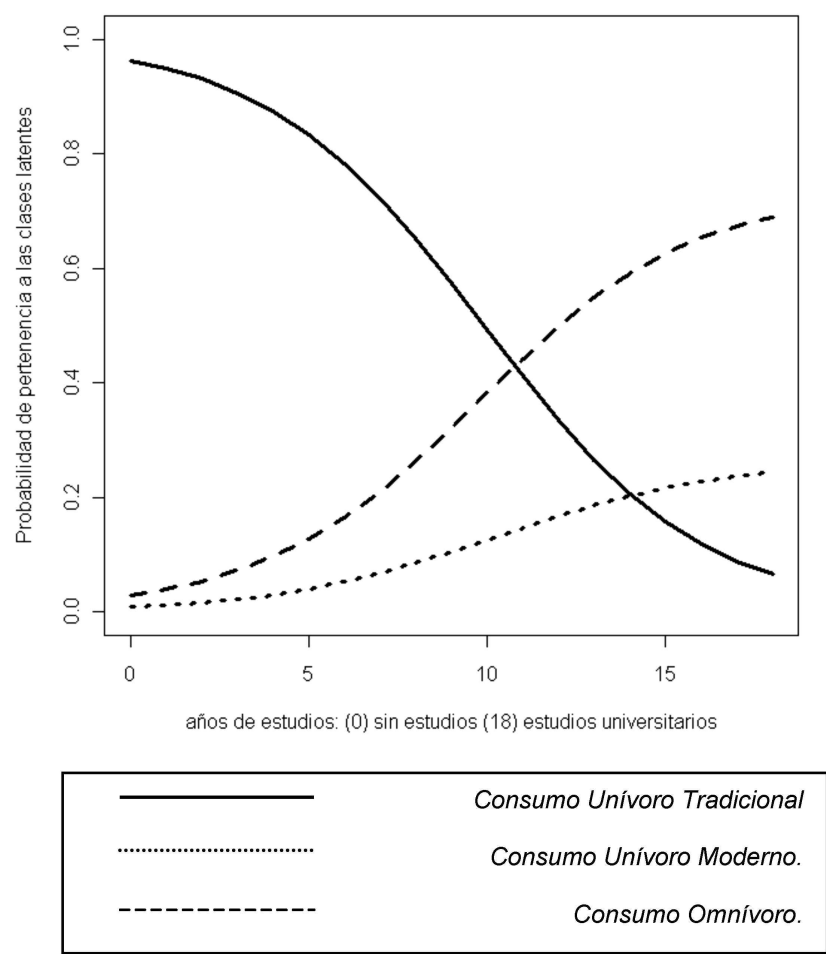

Fuente: Encuesta de Hábitos y Prácticas Culturales 2006-2007 y elaboración propia.

Tal y como señalaban López-Sintas, García-Álvarez y Filimon (2008: 97) para poder contrastar si existen evidencias en España que den apoyo al argumento Omnívoro-Unívoro (Peterson y Simkus; DiMaggio) o al argumento de la homología (Bourdieu), tenemos que encontrar patrones probabilísticos de consumo de música que puedan explicar la asociación que hay entre los diferentes géneros y las características socio-estratificatorias de aquellos individuos que los consumen.

En nuestro LCA hemos podido comprobar que existe un claro patrón de consumo omnívoro que soslaya la univoridad de alta cultura. Utilizando los niveles educativos como variable proxy de estratificación social, en la tabla 6 se comprueba como las probabilidades de pertenecer a la clase omnívoro frente a la clase unívora tradicional aumentan conforme aumenta el nivel de estudios de los individuos. Este efecto lo hemos representado gráficamente a través de la probabilidad de pertenecer a cada una de las tres clases latentes según los años 
de estudios (figura 8). El gráfico se lee del siguiente modo: A medida que aumenta el nivel educativo, las probabilidades de ser omnívoro aumentan. La probabilidad condicional de ser omnívoro pasa de poco más del $15 \%$ para los individuos sin estudios a más del $60 \%$ para los individuos con estudios universitarios. Por el contrario, la clase de consumo unívoro tradicional está fundamentalmente ligada a bajos niveles educativos. La población que no tiene estudios tiene una probabilidad de pertenecer a la clase unívora tradicional de más del $80 \%$, mientras que las probabilidades para personas con estudios universitarios no llegan al $10 \%$.

El hecho de tener hijos a su cargo, es una característica social que disminuye tanto la probabilidad de ser omnívoro como de ser unívoro moderno (ver tabla 3). Las personas adultas muestran también un consumo más omnívoro, tal y como señalaron Chan y Goldthorpe (2007c: 11), destacando la cohorte de los 30 a los 40 años, pero, al contrario de lo que obtuvieron dichos autores, no hemos encontrado diferencias significativas entre mujeres y hombres.

El nivel educativo también tiene efecto sobre las probabilidades de ser unívoro moderno frente a unívoro tradicional. Sin embargo, el efecto es ligeramente menor que en el consumo omnívoro (ver figura 8). La edad, en este caso, juega un papel opuesto. La cohorte más joven es la que presenta un consumo más moderno y menos tradicional. Además, el consumo unívoro moderno es más común entre hombres que entre mujeres.

\section{DISCUSIÓN}

A lo largo de este trabajo empírico hemos estudiado el impacto que tienen los procesos de estratificación social sobre las prácticas culturales. No puede analizarse rigurosamente el consumo cultural en sus distintas vertientes si no es acudiendo a alguno de los instrumentos que den cuenta de los procesos de fragmentación social. Ahora bien, el modo de aproximarnos a las relaciones entre estratificación social y consumo cultural puede marcar inevitablemente las conclusiones obtenidas. Los cálculos de probabilidades deducidos tras nuestros primeros análisis de regresión logística nos permitieron afirmar que, si bien las personas ubicadas en lo más alto del espacio social tenían más probabilidades de acudir a eventos culturales, otras variables sociodemográficas podían predecir mejor dichas prácticas. Con el propósito de darle una visión más relacional y menos causal a los vínculos entre prácticas culturales y estratificación social, realizamos un análisis de correspondencias múltiples. De este análisis concluimos que, en materia de preferencias, las clases sociales que se encontraban más alejadas en el espacio social, mantenían gustos bien distinguidos.

No obstante, ambos análisis no han dado cuenta de toda la complejidad técnica y teórica que exige el estudio de las prácticas y consumos culturales, centrándose únicamente en la probabilidad de practicar un hábito dado (en el caso del primer análisis de regresión logística) o en las relaciones entre estratos y gus- 
tos preferentes (en el caso del análisis de correspondencias). El análisis de clases latentes nos ha permitido captar en el ámbito de la música grabada tanto las preferencias, en términos de probabilidades condicionales en cada una de las clases latentes, como la capacidad de consumir un mayor o menor número de géneros. Esta tipo de análisis presenta un importante -aunque salvable- problema técnico. Exige un diseño de encuesta en el que se de al entrevistado la oportunidad de dar cuenta de todos los géneros que consume habitualmente y no sólo su preferido. Lamentablemente, no existen encuestas recientes en nuestro país que incluyan esta forma de recoger la actividad cultural, si, además, queremos que contengan variables sociodemográficas con las que poder construir modelos de clase social o estatus. Creemos que el modelo de cuestionario más óptimo será aquel que incluya, tanto la posibilidad de informar sobre los diferentes géneros y prácticas culturales que realice o consume el entrevistado, como aquellos géneros y prácticas que tiene como preferidas (para más información véase Silva, 2006). Dicho de otro modo y utilizando un ejemplo, el cuestionario debería incluir la posibilidad de incorporar los géneros musicales que consume y, además, su género preferido. Sería conveniente, por otra parte, incluir preguntas que den cuenta de las prácticas y conocimientos concretos sobre la esfera de las artes, de modo que, tal y como hace Bourdieu, pudiéramos recoger no ya la frecuencia de una práctica determinada (como visitar museos, galerías o monumentos) sino el conocimiento sobre pintores, compositores de música clásica o escritores contemporáneos de obras de teatro. Obtendríamos así, el patrón más exacto posible del material cognitivo en la esfera artística de los entrevistados y evitaríamos el sesgo de la «deseabilidad social» que producen las preguntas de respuestas categóricas en el ámbito del consumo, las prácticas y los gustos culturales (Peterson, 2007: 303).

Asimismo, y con el propósito de promover la triangulación metodológica en este campo, abogamos también por el uso de técnicas cualitativas, como las entrevistas en profundidad o los grupos de discusión, que den fe de los significados culturales de fenómenos como el de la omnivoridad. La prácticamente nula presencia de este tipo de estudios en nuestro país, y la escasez en el esfera internacional (véase Zavisca, 2005) hacen necesaria la apelación por esta vía de análisis.

\section{CONCLUSIÓN}

De los tres argumentos presentados al principio de este artículo, y tras examinar pormenorizadamente los tres análisis presentados, el único que parece no tener validez en la sociedad española contemporánea es el argumento de la individualización. Las teorías posmodernas, que defendían la perdida de influencia de los efectos de clase sobre las formas culturales, encuentran aquí evidencias en su contra. Las prácticas y gustos culturales distinguidos en nuestro país siguen estando vinculados mayormente a los estratos mejor posicionados en el espacio 
social, si bien la validez del argumento de la homología parece estar dando paso nuevos modos de estratificación del consumo cultural, esta vez, a través de la modalidad de consumo ${ }^{12}$.

Tras realizar nuestro análisis de clases latentes, no hemos encontrado un patrón de consumo snob, es decir, un patrón de consumo unívoro de alta cultura como sostiene el argumento de la homología. El consumo highbrow en España se da preferentemente entre aquellos individuos que tienen un patrón de consumo omnívoro, tal y como ya habían señalado Chan y Goldthorpe (2006), y López-Sintas, García-Álvarez y Filimon $(2002,2008)$. En este sentido, «la teoría del gusto de Bourdieu podría ser actualizada con nuevos hechos» (2008: 99) ya que los estratos sociales mejor posicionados podrían estar reconfigurando sus privilegios y distinciones de clase a través de nuevos modos de consumo más eclécticos y variados. Dicho de otro modo, «el número de géneros que una persona consume está en función de su estatus socioeconómico» (DiMaggio, 1987: 444). Este hecho no es baladí desde el punto de vista teórico. Los estilos de vida asociados a los consumos culturales son en las sociedades contemporáneas más importantes que otros consumos materiales a la hora de configurar los espacios comunes entre círculos sociales particulares (Chan y Goldthorpe, 2006: 19). Por otro lado, frente a lo realizado por otros autores (López-Sintas, García-Álvarez y Filimon, 2008; Chan, 2010; entre otros) nosotros si que hemos mantenido las diferencias entre los géneros que son considerados de baja cultura, encontrando así evidencias de una distinción entre un patrón unívoro ligado a géneros de origen tradicional, folclórico o de raíz popular, frente a un patrón unívoro de origen contemporáneo y ligado a fenómenos subculturales urbanos (pop/rock, rap/hiphop, electrónica, etc.). Por ende, haber encontrado modalidades de consumo musical particulares aporta una nueva evidencia empírica de la existencia de esquemas cognitivos y de proceso de información comunes para cada estrato social.

Esta distinción de consumos unívoros confirma lo ya comprobado por nuestros análisis de regresión logística en la asistencia a eventos culturales así como por otros autores. Hablamos de las diferencias entre las diferentes generaciones o grupos de edad. En las sociedades actuales han aparecido unos comportamientos y preferencias culturales entre las cohortes jóvenes que constituyen un conjunto lo suficientemente estable y coherente, como para distinguir a estos grupos de edad del resto de la población (Ariño, 2006). Además, la asistencia a eventos considerados de alta cultura como el teatro, la danza, los museos o las

\footnotetext{
${ }^{12}$ Debido a las deficiencias en el diseño de la Encuesta de Hábitos y Prácticas Culturales (Ministerio de Cultura, 2007), no hemos podido elaborar esquemas de clases, estatus o prestigio social con los que replicar las conclusiones que López-Sintas, García-Álvarez y Filimon $(2002 ; 2008)$ obtuvieron con datos de la sociedad española de mediados de la década de los noventa. Es por ello que, las conclusiones obtenidas al utilizar el nivel educativo como variable proxy de la estratificación social, no puede ser más que un indicio de un cambio en los patrones de estratificación en el consumo cultural.
} 
exposiciones está más ligada a las cohortes de mayor edad. Según este autor, y tal y como nuestros resultados han sacado a la luz, el consumo de música por parte de estas cohortes se caracteriza por una alta puntuación en rock/pop y escasa para los géneros más distinguidos. Del mismo modo, los géneros musicales y las prácticas de alta cultura han estado tradicionalmente ligados a las cohortes más maduras como ya demostraron Katz-Gerro (2002) y Ariño et al. (2006). Finalmente, cabría señalar que también hemos encontrado diferencias entre sexos en materia de consumo cultural. Los hombres tienen preferencias por los géneros musicales de carácter moderno, mientras que las mujeres tienen mayor probabilidad de asistir a eventos catalogados como alta cultura. A pesar de esto, no hemos encontrado diferencias significativas entre hombres y mujeres a la hora de predecir el comportamiento de consumo musical omnívoro.

\section{BIBLIOGRAFÍA}

Ariño, A., Castelló, R., Hernández, G. M. y Llopis, R. (2006): La participación cultural en España. Madrid: Fundación Autor

Bauman, Z. (1988): Freedom. Milton Keynes: Open University Press.

(2002): Society Under Siege. Cambridge: Polity Press.

BECK, U., (1992): Risk Society: Towards a New Modernity. London: Sage.

BELTRÁN, M. (2003): «Accionistas y managers profesionales: ¿sigue siendo capitalista el capitalismo?», Revista Española de Sociología, 3, 7-26

Bourdieu, P. (2006): La Distinción. Criterio y bases sociales del gusto. Madrid: Taurus

BRYSON, B. (1996): «Anything But Heavy Metal: Symbolic Exclusion and Musical Dislikes», American Sociological Review, 61: 5, pp.884-899

CARABAÑA, J. y Gómez Bueno, C. (1996): Cuadernos metodológicos: Escalas de prestigio profesional, Madrid: Centro de Investigaciones Sociológicas

Chan, T.W. (2010): Social Stratification and Cultural Consumption. Cambridge: Cambridge University Press

Chan, T.W. y GoldTHORPe J. H. (2005): «The Social Stratification of Theatre, Dance and Cinema Attendance» Cultural Trends, 14, pp. 193-212

(2006): «Social Stratification of Cultural Consumption Across Three Domains: Music, Theatre, Dance and Cinema, and the Visual Arts», disponible en http://users.ox.ac.uk/ sfos0006/papers/xdomain3.pdf [consulta: 20-7-2010]

(2007a): «Class and status: The Conceptual Distinction and its Empirical Relevance» American Sociological Review, 72, pp. 512-532

(2007b): «Social Stratification and Cultural Consumption: The Visual Arts in England» Poetics. 35, pp. 168-190

(2007c): «Social Stratification and Cultural Consumption: Music in England» European Sociological Review, 23, 1, pp. 1-19

Dimaggio, P. (1987): «Classification in art. American Sociological Review, 52, 440455

Dimaggio, P. y Useem, M. (1978): «Social class and arts consumption. Theory and Society, 5 , pp. 141-161

Dayton, C. M y McReady, G. B. (1988): «Concomitant-Variable Latent Class Models». Journal of the American Statistical Association, 83, 401, pp. 173-178

EMPIRIA. Revista de Metodología de Ciencias Sociales. N. 22, julio-diciembre, 2011, pp. 141-172. ISSN: $1139-5737$ 
ERIKSON, R., y GoldThORPe, J. H. (1992): The constant Flux, Oxford: Clarendon Press Oxford.

Erikson, R., Goldthorpe, J. H., y Portocarero, L. (1979): «International Class Mobility in Three Western European Countries». British Journal of Sociology, 30, pp. 415-441

GANZEBOOM, H. (1982): «Explaining differential participation in high-cultural activities: a confrontation of information-processing and status seeking theories». En: GANZEBOOM, H. B. G., DE GrAAF, M. y TREIMAN, D. J. (1992): «A Standard International Socio-Economic Index of Occupational Status», Social Science Research, núm. 21, 1 , pp. $1-56$

GIDDENS, A., (1991): Modernity and Self-identity: Self and Society in the Late Modern Age. Cambridge: Polity

GOLDTHORPE, J. H. (1968): The Afluent worker: industrial attitudes and behaviour. London: Cambridge.

(2010): De la sociología. Números, narrativas e integración de la investigación y la teoría. Madrid: CIS.

GüVELI, A. (2006): New social classes within the service class in the Netherlands and Britain. Adjusting the EGP class schema for the technocrats and the social and cultural specialists. Nijmegen: Dissertation Radboud University Nijmegen.

HagenaArs, J. A. y A. L. McCutcheon, eds. (2002): Applied Latent Class Analysis. Cambridge: Cambridge University Press.

JENkINS, R. (2002): Pierre Bourdieu. London: Routledge revised edition

Katz-Gerro, T. (2002): «Highbrow Cultural Consumption and Class Distinction in Italy, Israel, West Germany, Sweden, and the United States» Social Forces, 81, 1, pp. 207-229

KrAAYKAMP, G., y DiJKSTRA, K., (1999): «Preferences in leisure time book Redding: a study on the social differentiation in book Redding for the Netherlands.» Poetics, 26, pp. 203-234

LAHIRE, B. (2008): «The individual and the mixing of genres: Cultural dissonance and self-distinction». Poetics, 36: pp.166-188

LaZarsfeld, P.F. y Henry, N.W. (1968), Latent Structure Analysis, Boston, Mass.: Houghton Mifflin Company.

LÓPEZ-SinTAS, J., y GARCÍA-ÁlVAREZ, M. E., (2002): «Omnivores show up again: the segmentation of cultural consumers in Spanish social space». European Sociological Review, 18,3 , pp. 353-368

LóPez Sintas, J., García Álvarez, M. E. y Filimon, N. (2008): «Scale and periodicities of recorded music consumption: reconciling Bourdieu's theory of taste with Facts». The Sociological Review, 56, 1, pp. 78-100

Marshall, G., Swift, A. y Roberts, S. (2002) Against the odds? : Social class and social justice in industrial societies. Clarendon Press: Oxford

Ollivier, M. (2008): «Modes of openness to cultural diversity: Humanist, populist, practical and indifferent», Poetics, 36: pp.120-147

Ortega y Gasset, J. (2008): La deshumanización del Arte y otros ensayos de estética, Madrid: austral ciencias y humanidades

PAKUlski, J. y Waters, M. (1996): The Death of Class. London: Sage

PETERSON, R. A. (2005): «Problems in comparative research: the example of omnivorousness», Poetics, 33, pp. 257-282 (2007): «Comment on Chan and Goldthorpe: Omnivore, what's in a name, what's in a measure?», Poetics, 35, pp. 301-305

Peterson, R. A., y Simkus, A. (1992): «How musical tastes mark occupational status 
groups» en LAmont, M., y Fournier, M. (Eds.) Cultivating Differences: Symbolic Boundaries and the Making of Inequality. Chicago: University of Chicago Press, pp. 152-186

Peterson, R. A. y KeRn, R. M. (1996): «Changing highbrow taste: from snob to omnivore» American Sociological Review, 61, pp. 901-907

RYAN, J. (2000): «The production and consumption of culture: Essays on Richard A. Peterson's contributions to cultural sociology: A prolegomenon». Poetics, 28: pp.91-96

SiLva, E. (2006): «Distinction through visual art». Cultural Trends, 15, pp. 141-158.

Torche, F., (2007): «Social Status and cultural consumption: The case of Redding in Chile», Poetics, 35, pp. 70-92

VAn Rees, K., Vermunt, J. K., y Verboord, M. (1999): «Cultural classifications under discussion: latent class analysis of highbrow and lowbrow reading», Poetics, 26: pp.349-365

WARDE, A. (1997): Consumption, Food and Taste. London: Sage.

Warde, A., Wright, D., and GAYO-CAL, M. (2007): «Understanding Cultural Omnivorousness: Or the Myth of the Cultural Omnivore» Cultural Sociology, 1, 2: 143-164.

WILENSKY, H. L. (1964): «Mass society and mass culture: interdependence or independence?», American Sociological Review, 29, 2, pp. 173-197

Wuggenig, U. (2007): «Comments on Chan and Goldthorpe: Pitfalls in testing Bourdieu's homlogy assumptions using mainstream social science methodology Social Stratification and cultural consumption: The visual arts in England», Poetics, 35, pp. 306-316

Vermunt, J. K., y Magidson, J. (2006a): «Latent Class Analysis», disponible en http://www.statisticalinnovations.com/articles/Latclass.pdf [consulta: 27-7-2010]

(2006b) «Latent Class Cluster Analysis», disponible en http://www.statisticalinnovations.com/articles/lcclurev.pdf [consulta: 27-7-2010]

ZavisCA, J. (2005): «The Status of Cultural Omnivorism: A Case Study of Reading in Russia», Social Forces, 84, 2, pp. 1233-1255 


\section{ANEXO}

Tabla A1. Versiones del Esquema de Clases sociales EGP o CASMIN

\begin{tabular}{|c|c|c|c|c|c|}
\hline \multicolumn{2}{|c|}{$\begin{array}{l}\text { Versión } \\
\text { Clases) }\end{array}$} & \multicolumn{2}{|c|}{ Versión adaptada ( 7 clases) } & \multicolumn{2}{|c|}{ Versión mixta (7 clases) } \\
\hline I & $\begin{array}{lr}\text { Profesionales } & y \\
\text { administradores de grado } \\
\text { superior, gerentes de } \\
\text { grandes empresas y } \\
\text { grandes propietarios } \\
\text { (igual o más de } 10 \\
\text { empleados) }\end{array}$ & I & $\begin{array}{l}\text { Profesionales } \\
\text { administradores de grado } \\
\text { superior, gerentes de } \\
\text { grandes empresas y grandes } \\
\text { propietarios (igual o más de } \\
10 \text { empleados) }\end{array}$ & I y II & $\begin{array}{l}\text { Profesionales, } \\
\text { administradores, } \\
\text { técnicos y gerentes de } \\
\text { grandes y pequeñas } \\
\text { empresas }\end{array}$ \\
\hline II & $\begin{array}{lr}\text { Profesionales } & y \\
\text { administradores de grado } \\
\text { inferior, técnicos de grado } \\
\text { superior, gerentes de } \\
\begin{array}{l}\text { pequeñas empresas, } \\
\text { supervisores de "no } \\
\text { manuales" }\end{array}\end{array}$ & II & $\begin{array}{lrr}\text { Profesionales } & \text { y } \\
\text { administradores } & \text { de } & \text { grado } \\
\text { inferior, técnicos de } & \text { grado } \\
\text { superior, gerentes } & \text { de } \\
\text { pequeñas } & \text { empresas, } \\
\text { supervisores } & \text { de } & \text { "no } \\
\text { manuales" } & & \\
\end{array}$ & & \\
\hline IIIa & $\begin{array}{l}\text { Empleados no manuales } \\
\text { (rutina) de grado más alto } \\
\text { (administración } \\
\text { comercio) }\end{array}$ & III & $\begin{array}{l}\text { Empleados no manuales } \\
\text { (rutina) }\end{array}$ & IIIa & $\begin{array}{lr}\text { Empleados no } \\
\text { manuales (rutina) de } \\
\text { grado más alto } \\
\text { (administración } \\
\text { comercio) }\end{array}$ \\
\hline IIIb & $\begin{array}{l}\text { Empleados no manuales } \\
\text { (rutina) de grado más bajo } \\
\text { (ventas y servicios). }\end{array}$ & & & IIIb & $\begin{array}{l}\text { Empleados no } \\
\text { manuales (rutina) de } \\
\text { grado más bajo } \\
\text { (ventas y servicios). }\end{array}$ \\
\hline IVa & $\begin{array}{l}\text { Pequeños propietarios, } \\
\text { artesanos, etc., con } \\
\text { empleados (menos de } 10 \\
\text { empleados) y }\end{array}$ & IV & Pequeña Burguesía. & IV & Pequeña Burguesía. \\
\hline $\mathrm{IVb}$ & $\begin{array}{l}\text { Pequeños propietarios, } \\
\text { artesanos, etc., sin } \\
\text { empleados (autónomos) }\end{array}$ & & & & \\
\hline IVc & $\begin{array}{l}\text { Agricultores y pequeños } \\
\text { propietarios agrícolas con } \\
\text { empleados }\end{array}$ & & & & \\
\hline $\mathrm{V}$ & $\begin{array}{l}\text { Técnicos de nivel más } \\
\text { bajo y supervisores de } \\
\text { trabajadores manuales }\end{array}$ & V & $\begin{array}{l}\text { Técnicos de nivel más bajo } \\
\text { y supervisores de } \\
\text { trabajadores manuales }\end{array}$ & V & $\begin{array}{lr}\text { Técnicos de } & \text { nivel } \\
\text { más bajo } & \text { y } \\
\text { supervisores } & \text { de } \\
\text { trabajadores } & \\
\text { manuales } & \\
\end{array}$ \\
\hline VI & $\begin{array}{l}\text { Trabajadores manuales } \\
\text { cualificados. }\end{array}$ & VI & $\begin{array}{l}\text { Trabajadores manuales } \\
\text { cualificados. }\end{array}$ & VI & $\begin{array}{l}\text { Trabajadores } \\
\text { manuales } \\
\text { cualificados. }\end{array}$ \\
\hline VIIa & $\begin{array}{l}\text { Trabajadores manuales } \\
\text { semi, y no cualificados } \\
\text { (no agrícolas). }\end{array}$ & VII & $\begin{array}{l}\text { Trabajadores manuales } \\
\text { semi- y no cualificados }\end{array}$ & VII & $\begin{array}{l}\text { Trabajadores } \\
\text { manuales semi- y no } \\
\text { cualificados }\end{array}$ \\
\hline VIIb & $\begin{array}{l}\text { Trabajadores agrícolas por } \\
\text { cuenta ajena (jornaleros). }\end{array}$ & & & & \\
\hline
\end{tabular}

Fuente: Erikson y Goldthorpe (1992); Chan y Goldthorpe (2007a) y elaboración propia.

EMPIRIA. Revista de Metodología de Ciencias Sociales. N. ${ }^{\circ} 22$, julio-diciembre, 2011, pp. 141-172. 